\title{
Ceramides and Skin Function
}

\author{
Luisa Coderch, Olga López, Alfonso de la Maza and José L. Parra
}

Instituto de Investigaciones Químicas y Ambientales de Barcelona, Barcelona, Spain

\section{Contents}

Abstract $\ldots \ldots \ldots \ldots \ldots \ldots$

1. Current Concepts on Structure and Function of Stratum Corneum . . . . . .

1.1 Lamellar Bilayer Generation, Maturation and Substructure . . . . . . . .

1.2 Covalently Bound Envelope . . . . . . . . . . . . . . . . . . . . . . 110

2. Lipids Derived from Lamellar Bodles . . . . . . . . . . . . . . . . . . . .

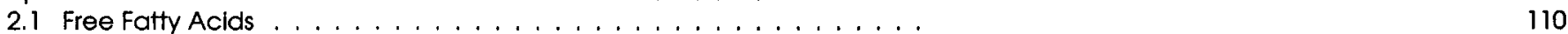

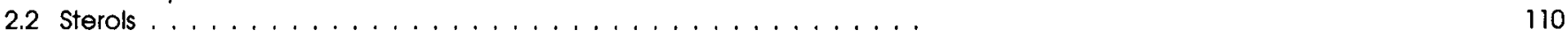

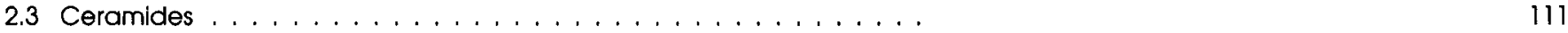

3. The Ceramldes in the Phase Behavior of Intercellular Lipids . . . . . . . . . . .

4. Relationship Between Ceramides and Barrier Function of Skin . . . . . . . . .

4.1 Effect of Anatomical Site, Sex, Age, and Season . . . . . . . . . . . . . .

4.2 Effect of Barrier Damage Induced by External Factors . . . . . . . . . . . . 119

4.3 Pathological Skin Disorders . . . . . . . . . . . . . . . . . . . . . . . 121

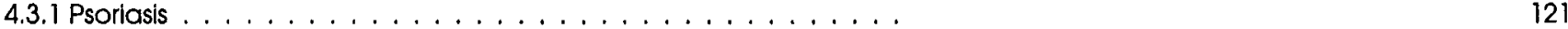

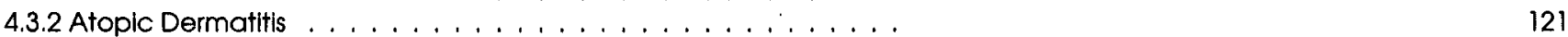

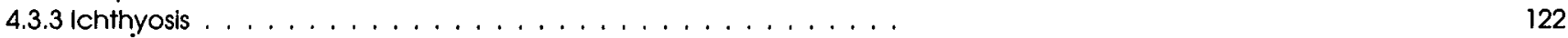

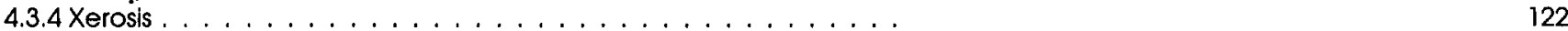

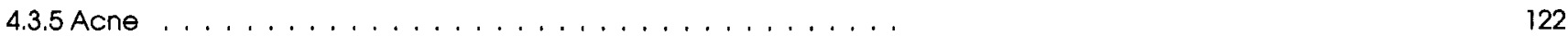

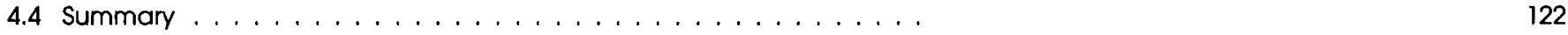

5. Ceramide Supplementation in Skin Disorders . . . . . . . . . . . . . . . .

6. Enhanced Ceramide Synthesis in Skin Disorders Through Delivery of Precursors

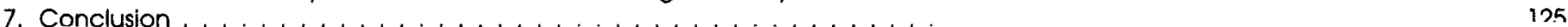

\section{Abstract}

Ceramides are the major lipid constituent of lamellar sheets present in the intercellular spaces of the stratum corneum. These lamellar sheets are thought to provide the barrier property of the epidermis. It is generally accepted that the intercellular lipid domain is composed of approximately equimolar concentrations of free fatty acids, cholesterol, and ceramides. Ceramides are a structurally heterogeneous and complex group of sphingolipids containing derivatives of sphingosine bases in amide linkage with a variety of fatty acids. Differences in chain length, type and extent of hydroxylation, saturation etc. are responsible for the heterogeneity of the epidermal sphingolipids.

It is well known that ceramides play an essential role in structuring and maintaining the water permeability barrier function of the skin. In conjunction with the other stratum corneum lipids, they form ordered structures. An essential factor is the physical state of the lipid chains in the nonpolar regions of the bilayers. The stratum corneum intercellular lipid lamellae, the aliphatic chains in the ceramides and the fatty acids are mostly straight long-chain saturated compounds with a high melting point and a small polar head group. This means that at physiological temperatures, the lipid chains are mostly in a solid crystalline or gel state, which exhibits low lateral diffusional properties and is less permeable than the state of liquid crystalline membranes, which are present at higher temperatures.

The link between skin disorders and changes in barrier lipid composition, especially in ceramides, is difficult to prove because of the many variables involved. However, most skin disorders that have a diminished barrier function present a decrease in total ceramide content with some differences in the ceramide pattern.

Formulations containing lipids identical to those in skin and, in particular, some ceramide supplementation could improve disturbed skin conditions. Incomplete lipid mixtures yield abnormal lamellar body contents, and disorder intercellular lamellae, whereas complete lipid mixtures result in normal lamellar bodies and intercel- 
lular bilayers. The utilization of physiological lipids according to these parameters have potential as new forms of topical therapy for dermatoses. An alternative strategy to improving barrier function by topical application of the various mature lipid species is to enhance the natural lipid-synthetic capability of the epidermis through the topical delivery of lipid precursors.

The bilayer lipid matrix of cell membranes is composed of a heterogeneous mixture of different lipids, e.g. phospholipids, sphingolipids, and cholesterol. With the exception of sphingomyelin, sphingolipids are usually minor components of membranes. However, the sphingolipids and their breakdown products are now thought to be involved in various cellular processes, e.g. transport functions, immunological activity, cell growth, and differentiation. ${ }^{[1-5]}$ Consequently, there is a growing interest in the study of the structure and properties of sphingolipids. ${ }^{[6-8]}$

The essential molecular features of sphingolipids are: (i) a hydrophobic backbone called ceramide, which consists of a sphingosine base with an amide-linked fatty acid; and (ii) a polar head group. The ceramide, itself, is synthesized in the endoplasmic reticulum and transported to the Golgi apparatus, where it is converted to cerebroside, ganglioside, or sphingomyelin. ${ }^{[9]} \mathrm{Al}-$ though ceramides act as a precursor for cerebroside, ganglioside, and sphingomyelin, very low levels of free ceramides are found in membranes.

Recently, it has been demonstrated that certain environmental signals that induce cell growth inhibition, cell differentiation, programmed cell death (apoptosis), and down-regulation of the $c-m y c$ proto-oncogene rapidly increase intracellular ceramide concentrations by increasing sphingomyelin turnover or by increasing de novo synthesis. ${ }^{[10-17]} \mathrm{A}$ role for the generated ceramides in mediating some of the activities of these extracellular signals (e.g. tumor necrosis factor- $\alpha$, interferon- $\gamma$ or 1- $\alpha, 25$-dihydroxyvitamin $D_{3}$ ) has been demonstrated with the use of water-soluble, cellpermeable ceramide analogues. ${ }^{[11,13,18,19]}$ These studies have established a potential signaling pathway involving sphingomyelin hydrolysis with the generation of ceramides as putative second messenger molecules. Ceramides have been shown to induce phosphorylation of the epidermal growth factor receptor, possibly by activating a protein kinase. ${ }^{[20,21]}$ A novel ceramide-activated protein phosphatase which may be involved in transducing the effects of ceramides has been identified. ${ }^{[14,22,23]}$ Thus, the second messenger ceramide can dispatch the signal via activation of a protein kinase or a protein phosphatase. In skin, little is known about the role of sphingolipids in signaling events. In keratinocytes, extracellular and intracellular ceramides play important different roles. Intracellular ceramides cause differentiation of keratinocytes. Current knowledge of sphingolipid signaling in epidermal homeostasis has recently been reviewed. [24]

It is well known that the permeability barrier of the skin, which prevents water loss and penetration of harmful chemicals from the environment, is localized in the horny layer (stratum corneum) of the epidermis. ${ }^{[25,26]}$ Intracellular ceramides are present in large amounts in the stratum corneum and are the major lipid constituents of the lamellar sheets present in the intercellular spaces of the stratum corneum. These lamellar sheets are believed to provide the barrier property of the epidermis. This review will be mainly focused on the structural function of the ceramides as part of the lipid barrier of the skin.

The superficial cornified layer of the stratum corneum of the epidermis of terrestrial vertebrates has evolved to provide a barrier to water permeation, which is essential for survival in a dry environment. ${ }^{[25,26]}$ It has been known for decades that this barrier is provided by lipids, but it was only during the 1980s that the molecular structure and physical arrangement of these lipids were defined.

The stratum corneum is composed of corneocytes, flattened dead cells, which are embedded in lamellar lipid regions. There is a continuous renewal of cells in the basal layer of the epidermis. These cells are subsequently transported to the upper layers in the epidermis. The composition of lipids changes markedly during apical migration through successive epidermal layers. When the differentiation process is accomplished (i.e. in the stratum corneum), the lipid composition changes markedly, the phospholipids are degraded enzymatically into glycerol and the free fatty acids and glucosylceramides into ceramides. The main constituents of stratum corneum lipids are thus cholesterol, free fatty acids and ceramides. Stratum corneum ceramides represent a unique heterogeneous group of at least eight ceramides that differ from each other by the head-group architecture and by the mean fatty acid chain length. In addition to the free lipids of the stratum corneum matrix, there are at least two species of ceramides covalently bonded to the corneocyte protein envelope.

The function of all these ceramides is the subject of much investigation. They are known to be critical in the barrier function of the epidermis but the influence of their chemical structure and their macromolecular organization is still a matter of speculation. This paper will review the knowledge of the structure of these compounds as well as their essential role in the stratum corneum

\section{Current Concepts on Structure and Function of Stratum Corneum}

The stratum corneum is viewed currently as a layer of protein- 
enriched corneocytes embedded in a lipid-enriched, intercellular matrix, ${ }^{[25]}$ the so-called 'bricks and mortar' model. ${ }^{[27,28]}$ The 'bricks' are corneocytes surrounded by a cornified cell envelope made up of proteins, mainly loricrin and involucrin, and covalently bound to the hydroxyceramide molecules of a lipid envelope. In turn, these 'bricks' are embedded in a 'mortar' of lipid bilayers. ${ }^{[29-31]}$ The so-called 'mortar' contains a variety of intercellular lipids including, ceramides, free sterols and sterolesters, cholesterol sulfate, and free fatty acids.

The evidence for such protein-lipid sequestration is based on freeze-fracture replication, histochemical, biochemical, cell fractionation, cell separation, and physical chemical studies (reviewed in Elias $\left.{ }^{[27]}\right)$. Freeze-fracture analysis reveals stacks of intercellular bilayers in the intercellular spaces. Moreover, histochemical stains also show the membrane domains of the stratum corneum to be enriched in neutral lipids, especially when these stains are applied to frozen sections. Furthermore, analysis of isolated peripheral membrane domains has shown that: (i) the bulk of stratum corneum lipids are in stratum corneum interstices; (ii) the lipid composition of these preparations is virtually identical to that of the whole stratum corneum; and (iii) the freeze-fracture pattern of membrane multilayers, previously described in whole stratum corneum, is duplicated in the membrane preparations. Finally, X-ray diffraction and electron-spin resonance studies have identified that all the bilayer structures, as well as physiological lipid-based thermal phenomena, are localized to these membrane domains. ${ }^{[32]}$

Although the intercellular epidermal lipids only account for about $15 \%$ of the stratum corneum weight (with the remainder being $15 \%$ water and $70 \%$ proteins), they are essential components of a suitable barrier function and prevent, in combination with the socalled hydrolipidic layer, excessive transepidermal water loss. ${ }^{[27-33]}$ The unique molecular organization into bilayer units with alternating electron-dense and electron-lucent lamellae not only imparts the impermeability of stratum corneum but also provides a selective permeability for lipophilic substances. ${ }^{[34,35]}$ It has been suggested that quantitative differences in lipid content are more accurate than stratum corneum thickness in predicting regional variations in skin permeability. ${ }^{[36]}$ Thus, the barrier properties of the skin will largely depend on the intactness of the lipid lamellae in the intercellular spaces of the stratum corneum. Both total content and the type of lipids appear to be important. ${ }^{[34-37]}$

\subsection{Lamellar Bilayer Generation. Maturation and Substructure}

Lamellar body exocytosis delivers the precursors of these bilayers to the intercellular spaces at the stratum granulosum-stratum corneum interface. ${ }^{[32]} \mathrm{A}$ transition can be observed from lamellar body-derived sheets into successively elongated membranes with the same substructure as lamellar body sheets which unfurl parallel to the plasma membrane ${ }^{[28,38,39]}$ (figure 1). End-to-end fusion of lamellar body-derived membrane sheets continues within the first two layers of the stratum corneum, giving rise to broad, uninterrupted membrane sheets, followed by compaction of adjacent membrane sheets into lamellar bilayer unit structures.

This change in structure correlates with a sequence of change in lipid composition, i.e. from the polar lipid-enriched mixture of glycosphingolipids, phospholipids, and free sterols present in lamellar bodies to the more nonpolar mixture, enriched in ceramides, free sterols, and free fatty acids that is present in the remainder of the stratum corneum. ${ }^{[32]}$ An explanation for the structural changes, consistent with the compositional changes and enzyme Iocalization data, is that the initial end-to-end fusion of unfurled lamellar body-derived sheets may be mediated by the initial degradation of phospholipids to free fatty acids by phospholipase $A_{2},{ }^{[4]}$ which occurs in abundance in lamellar bodies and in the stratum corneum interstices (figure 1). The subsequent transformation of elongated disks into the broad multilamellar membrane system required for barrier function is associated with the further, complete hydrolysis of residual glucosylceramides to ceramides with the action of $\beta$-glucocerebrosidase. ${ }^{[42]}$ Phosphosphingolipid sphingomyelin has recently also been proved to be the precursor of some epidermal ceramides, ${ }^{[43]}$ the presence of acid-sphingomyelinase with highest activity at $\mathrm{pH}$ 5.1-5.6 being important. ${ }^{[4]}$ These intercellular lipid lamellae may exist either in a solid crystalline gel or in a liquid crystalline phase, the degree of fatty acid unsaturation being responsible for the balance between these phases. ${ }^{[45]}$

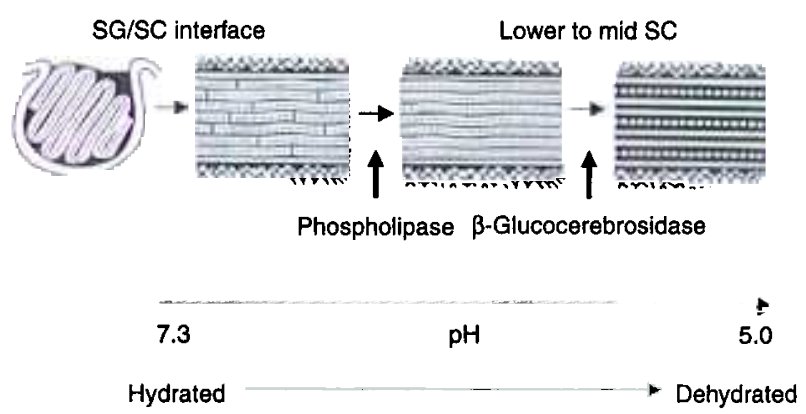

Fig. 1. Several of the steps required for the synthesis of the unit membrane found in the intercellular space of the stratum corneum (SC). Extracellular processing of polar lipids to nonpolar lipids is required for the sequential membrane modifications that lead to barrier formation. In addition, changes in extracellular $\mathrm{pH}$ and hydration may contribute to this sequence. SG = stratum granulosum (reproduced from Elias, ${ }^{[40]}$ with permission from Marcel Dekker). 
The entire multilamellar complex lies parallel outside the corneocyte surface, which has a hydrophobic envelope containing covalently bound ceramides. ${ }^{[46]}$

\subsection{Covalently Bound Envelope}

The membrane complex immediately outside the cornified envelope replaces the true plasma membrane during differentiation. ${ }^{[32]}$ Although a portion of this trilaminar structure survives exhaustive solvent extraction, it is destroyed by saponification. ${ }^{[29]}$ Lipid extracts of saponified fractions yield at least two very longchain, $\omega$-hydroxy acid-containing ceramides that are believed to be covalently attached to glutamine residues in the cornified envelope. ${ }^{[47,48]}$ Although the covalently bound envelope is enriched in $\omega$-hydroxy acid-containing ceramides, its complete composition is not known since both the initial solvent extraction of the intercellular lamellae and subsequent saponification could remove or destroy certain constituents of this structure. Given that this envelope remains after prior solvent extraction has rendered the stratum corneum porous, it is assumed that it does not constitute a barrier. It may function as a scaffold for the deposition and organization of lamellar body-derived, intercellular bilayers. However, a recent study ${ }^{[49]}$ has found a direct correlation between the amount of covalently bound ceramides and the barrier function of the skin. Finally, the origin of the covalently bound envelope remains unknown. It could originate from the pool of lipids deposited during lamellar body and/or Golgi apparatus secretion, and/or by in situ degradation of plasma membrane sphingolipids, such as sphingomyelin. ${ }^{50]}$

\section{Lipids Derived from Lamellar Bodies}

Lipids are relatively chemically inert and do not readily form hydrogen bonds with water. This 'hydrophobic effect' is the primary driving force for the formation of lipid aggregates. However, not all lipids form bilayers; membranes are generally formed by amphipathic molecules that contain a polar head group and an apolar alkyl chain. The alkyl chains align in parallel to form the hydrophobic domain whereas the polar head group forms the interface with aqueous domains. It is the subtle balance of forces between the alkyl chains and the polar group that governs the predisposition of a lipid to form a specific structure. ${ }^{[51,52]}$ In particular, the alkyl chain length and degree of saturation strongly influence the predisposition of lipid mixtures to form these structures.

It is well known that the intercellular lipid domain is composed of roughly equimolar concentrations of free fatty acids, cholesterol, and ceramides. The polar head groups of these lipids are un- usual for membrane-forming lipids in that they are all relatively small and bind water poorly.

\section{Free Fatty Acids}

The composition of free fatty acids in human stratum corneum is rather unique. They are predominantly saturated and range from 14-28 carbons in length and account for about $10 \%$ in weight of stratum corneum lipids. ${ }^{[46]}$ They mainly consist of palmitic

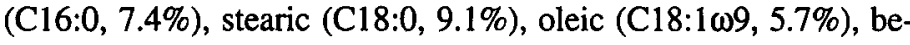
henic $(\mathrm{C} 22: 0,5.9 \%)$ and lignoceric $(\mathrm{C} 24: 0,26.9 \%)$ acids. ${ }^{[53]}$ This contrasts with the free fatty acid content of serum ${ }^{[54]}$ or sebum, indicating that free fatty acids are derived from de novo synthesis in the epidermis. The free fatty acids in the stratum corneum are not enriched in essential fatty acids, suggesting that these lipids do not play a significant structural role in the intercellular lipid domain. However, the principal role of essential fatty acids is presumably related to their ester derivatives linked to $\omega$-hydroxy acid-containing ceramides that are required for the formation of the $13 \mathrm{~mm}$ trilaminar unit (see section 3 ) as well as to the viability of the epidermis. Since the composition of the free fatty acid $\$$ in the stratum corneum does not reflect that of the underlying layers, this indicates that pathways for the degradation and/or recycling of unsaturated fatty acids exist. Overall, the fatty acid composition of the intercellular lipid plays an important role in the stratum corneum barrier and in the $\mathrm{pH}$ variations in the different stratum corneum layers. ${ }^{[46]}$

\subsection{Sterols}

The primary sterol found in the stratum corneum is cholesterol (27\%), though significant levels of cholesterol esters (10\%) and cholesterol sulfate (3\%) are also observed. ${ }^{[53]}$ Cholesterol is also a major component of mammalian plasma membranes; thus, it is the only major lipid class found in both of these systems. Although obtainable from nutritional (i.e. serum) sources, epidermal cholesterol is mainly synthesized in the epidermis. ${ }^{[55]}$ Owing to the hydroxyl group in position 3, representing the polar head group, cholesterol is roughly perpendicular to the bilayer surface and improves both plasticity and rigidity of the membranes. ${ }^{[46]}$ Although the amount of cholesterol sulfate present in the epidermis is rather low, it is important for the cell-cell cohesion of the stratum corneum. Its desulfatation by a steroid sulfatase is required for physiological desquamation of the stratum corneum. It has been observed that any alteration of the cholesterol metabolism in the epidermis leads to considerable disturbances of the cohesiondesquamation homeostasis of the horny cells, and to a disturbed barrier function. ${ }^{[56]}$ 


\subsection{Ceramides}

Ceramides are a structurally heterogeneous and complex group of sphingolipids containing mainly sphingosine, phytosphingosine or 6-hydroxysphingosine, $\mathrm{C} 18$-sphingoid bases in amide linkage with a variety of nonhydroxy, $\alpha$-hydroxy, or $\omega$ hydroxy acids ${ }^{[57,58]}$ (figure 2). These differences in type and extent of hydroxylation, together with the $\mathrm{N}$-acyl chain lengths and the presence of an additional acylation at the $\omega$-side of the $\mathrm{N}$-acyl group, account for the heterogeneity of the epidermal sphingolipids. ${ }^{[59]}$ They represent about $50 \%$ of the total lipid amount of the stratum corneum.

The initial nomenclature of ceramides was based on a series of numbers from 1-6 (the higher the number, the greater the polarity) in accordance with the six chromatographically separated ceramide fractions determined in pig skin. ${ }^{[59]}$ A new ceramide fraction has since been obtained in human skin with an intermediate polarity between ceramide (Cer) 3 and Cer $4^{[58]}$ and recently another ceramide with the same polarity as Cer 5 was found. ${ }^{[60]}$ Thus, there are at least eight major free ceramides present in the human stratum corneum matrix (Cer 1-8) [figure 3]. In addition, there are at least two major protein-bound ceramides that are

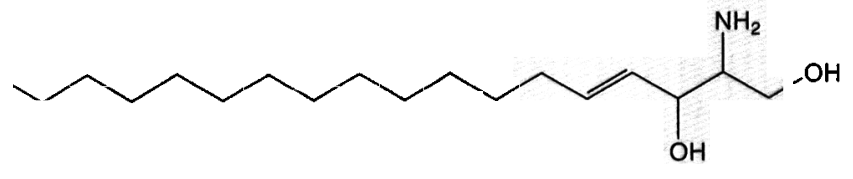

Sphingosine (S)

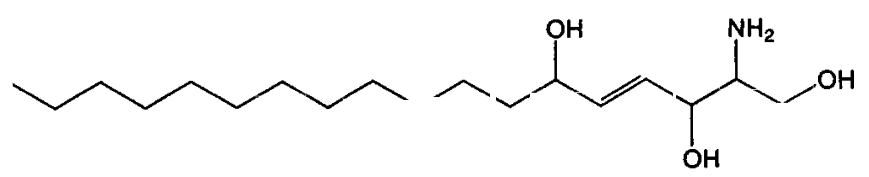

6-Hydroxysphingosine $(H)$

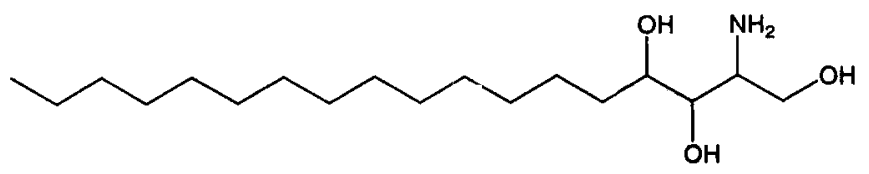

Phytosphingosine (P) covalently bonded to the corneocyte protein envelope (Cer A and B) [figure 3].

Progress in elucidation of epidermal ceramide structures has made possible a nomenclature based on their molecular structure instead of on their mobility on thin layer chromatography. This system, which makes use of individual characters, indicates the type of amide-linked fatty acid and the type of base (table I). ${ }^{[58-61]}$

As stated earlier in the section, the stratum corneum ceramides differ from one another by the architecture of the head group and by the fatty acid chain length. The fatty acid esterified to the amide of the sphingosine head group can be either $\alpha$-hydroxy or nonhydroxy fatty acids. The fatty acid chain lengths vary between 16 (Cer 5 [AS]) and 30-40 carbon atoms (Cer 1 [EOS]). Furthermore, Cer 1 (EOS) and Cer 4 (EOH) contain mainly linoleic acid linked to the $\omega$-hydroxy acids. All these differences in chemical structure of the ceramides (summarized in table I) are assumed to be important for the characteristic organization of stratum corneum lipids.

Serine palmitoyl transferase is the rate-limiting enzyme in sphingolipid synthesis producing an intermediate dihydrosphingosine (sphinganine) followed by $\mathrm{N}$-acylation. Inhibition of this

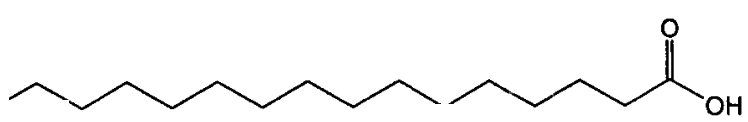

Nonhydroxy acid (N)

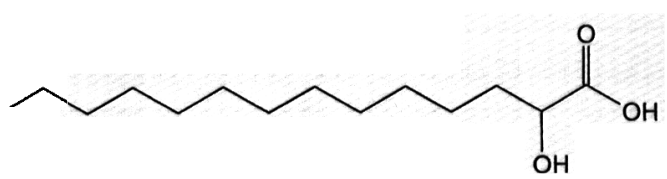

$\alpha$-Hydroxy acid (A)

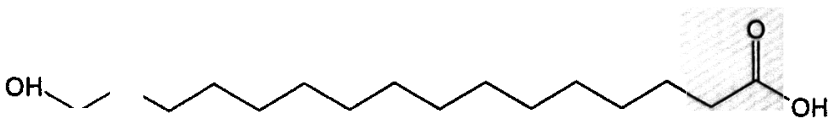

$\omega$-Hydroxy acid (O)

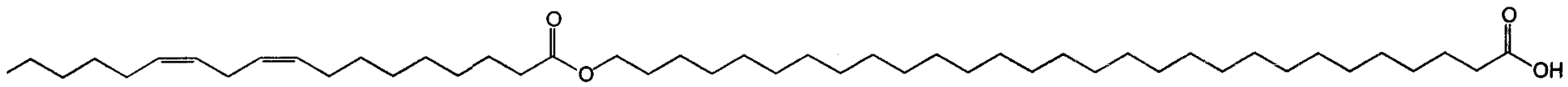

$\omega$-Acyl-oxyacid or esterified $\omega$-hydroxy acid (EO)

Fig. 2. Chemical structures of sphingoid bases and fatty acids which form, through amide linkage, the different ceramides present in the stratum corneum. 
a<smiles>CCCCCCCCCCCCCCCCCCCCCCOC(=O)CCCCCCCCCCCCCCCC</smiles>

Ceramide 1 (EOS)<smiles>CCCCCCCCCCCCCCCCCCCCCCC(C)CC</smiles>

(N)

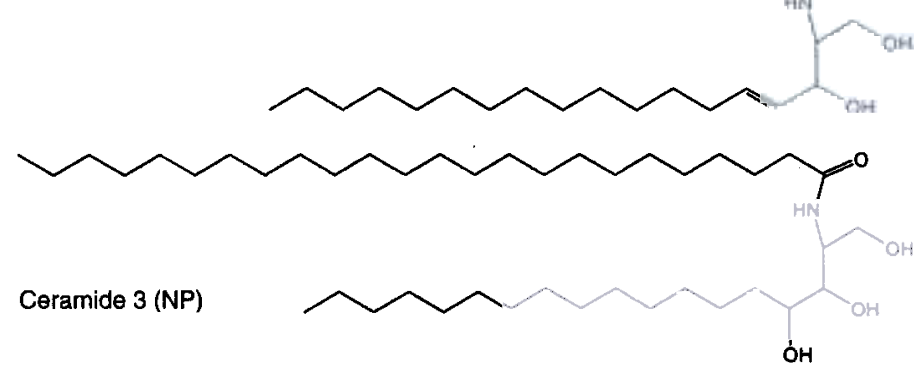

Ceramide 2 (NS)<smiles>CCCCCCCCCCCCC/C=C/C(O)C(N)CO</smiles>

Ceramide 3 (NP)<smiles>CCCCCC=CCC=CCCCCCCCC(=O)OCCCCCCCCCCCCCCCCCCCCCCCCCCCCCC(=O)NC(CO)C(O)CCC(O)CCCCCCCCCCCCCC(=O)O</smiles><smiles>CCCCCCCCCCCCC/C=C/C(O)C(CO)NC(=O)C(O)CCCCCCCCCCCCCCCCCCCCCC</smiles><smiles>CCCCCCCCCCCCCCCCCCCCCCCC(=O)NC(CO)C(O)CCCCCCCCCCCCCCCCC(C)(C)C(C)(C)C</smiles>

òn<smiles>CCCCCCCCCCCCCCCCCCCCCCC(O)C(=O)NC(CO)C(O)I(C)CCCCCCCCCCCCCC</smiles><smiles>CCCCCCCCCCCCCCCCCCCCCCC(O)C(=O)NC(CO)C(O)/C=C/C(O)CCCCCCCCCCCC</smiles>

b

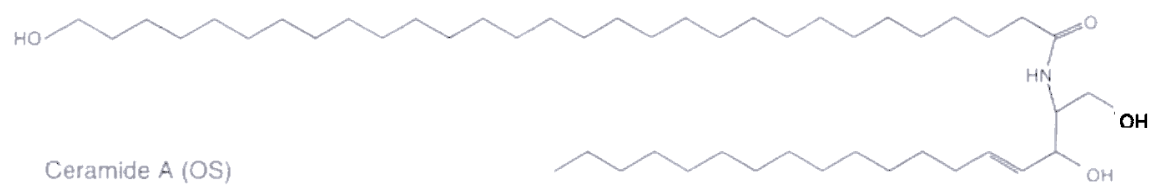<smiles>CCCCCCCCCCCCC(O)CCC(O)C(CO)NC(=O)CCCCCCCCCCCCCCCCCCCCCCCCCCCCCCCCO</smiles>

Fig. 3. Structures of the (a) eight major free ceramides and (b) two protein-bound ceramides of the human stratum corneum (reproduced from Robson et al., ${ }^{[58]}$ with permission). $\mathbf{A}=\alpha$-hydroxy acid; $\mathbf{E}=\omega$-acyl-oxyacid or esterified $\omega$-hydroxy acid; $\mathbf{H}=6$-hydroxysphingosine; $\mathbf{N}=$ nonhydroxy acid; $\mathbf{O}=\omega$-hydroxy acid; $\mathbf{P}=$ phytosphingosine; $\mathbf{S}=$ sphingosine. 
Table I. Free ceramides of human stratum corneum

\begin{tabular}{|c|c|c|c|c|}
\hline $\begin{array}{l}\text { Numerical } \\
\text { nam. }\end{array}$ & $\begin{array}{l}\text { Chemical } \\
\text { nam }\end{array}$ & Sphingoid base & Linked fatty acids & $\begin{array}{l}\text { Total ceramides } \\
\text { content in the SC }(\%)\end{array}$ \\
\hline & $\overline{\mathrm{EOS}}$ & Sphingosine & $\begin{array}{l}\text { Saturated } 30-40 \text { carbon chains, amide-linked } \omega \text {-hydroxy acids. Mainly } \\
\text { linoleate ester linked to } \omega \text {-hydroxyl group }\end{array}$ & 8 \\
\hline 2 & NS & Sphingosine & $\begin{array}{l}\text { Mainly saturated } 18,24,26 \text { and } 28 \text { carbon chains, amide-linked acids } \\
\text { (nonhydroxy acids) }\end{array}$ & 21 \\
\hline \multirow[t]{2}{*}{3} & NP & Phytosphingosine & $\begin{array}{l}\text { Mainly saturated } 18,24,26 \text { and } 28 \text { carbon chains, amide-linked acids } \\
\text { (nonhydroxy acids) }\end{array}$ & 13 \\
\hline & $\mathrm{EOH}$ & 6-Hydroxysphingosine & $\begin{array}{l}\text { Saturated } 30-40 \text { carbon chains, amide-linked } \omega \text {-hydroxy acids. Mainly } \\
\text { linoleate ester linked to } \omega \text {-hydroxyl group }\end{array}$ & 4 \\
\hline 5 & AS & Sphingosine & $\begin{array}{l}\text { Mainly saturated } 16,24 \text { and } 26 \text { carbon chains, amide-linked } \alpha \text {-hydroxy } \\
\text { acids }\end{array}$ & 18 \\
\hline 6 & $\mathrm{NH}$ & 6-Hydroxysphingosine & $\begin{array}{l}\text { Mainly saturated } 18,24,26 \text { and } 28 \text { carbon chains, amide-linked acids } \\
\text { (nonhydroxy acids) }\end{array}$ & 9 \\
\hline 7 & AP & Phytosphingosine & Mainly saturated 24 and 26 carbon chains, amide-linked $\alpha$-hydroxy acids & 4 \\
\hline 8 & $\mathrm{AH}$ & 6-Hydroxysphingosine & Mainly saturated 24 and 26 carbon chains, amide-linked $\alpha$-hydroxy acids & 22 \\
\hline
\end{tabular}

enzyme, with $\beta$-chloroalanine for example, has been shown to delay barrier repair after damage. ${ }^{\text {[62] }}$ Although both glucosylceramide and the phosphosphingolipid sphingomyelin are potential precursors of stratum corneum ceramides, it was assumed that all major subfractions are generated from glucosylceramides. ${ }^{\text {[2] }}$ Subsequent experiments demonstrated that epidermal sphingomyelin is also important an precursor of Cer 2 (NS) and Cer 5 (AS) and that $\omega-\mathrm{OH}$ Cer 1 (EOS) and Cer $4(\mathrm{EOH})$ only derive from glucosylceramide precursors. ${ }^{[43]} \mathrm{A}$ proposed pathway for production of stratum corneum ceramides is schematized in figure 4.

\section{The Ceramides in the Phase Behavior of Intercellular Lipids}

It is well known that ceramides play an essential role in structuring and maintaining the water permeability barrier function of the skin. ${ }^{[32,63,64]}$ However, in contrast with cellular membranes, which consist predominantly of phospholipids, ceramides located in the intercellular spaces are not able to form bilayer configurations by themselves. ${ }^{[65]}$ Nevertheless, in conjunction with cholesterol, and even more with free fatty acids and cholesterol sulfate, which are ionized at physiological $\mathrm{pH}$, they form ordered structures (see section 2). These arrays of hydrophobic chains construct lipid bilayers with closely packed interiors which dramatically reduce their permeability to water and solutes. ${ }^{[35,66,67]}$ However, the presence of lipid bilayers in the stratum corneum alone is insufficient to guarantee an impermeable water barrier.

One essential factor is the physical state of the lipid chains in the nonpolar regions of the bilayers. This is because in the stratum corneum intercellular lipid lamellae, the aliphatic chains in the ceramides and the fatty acids, both free and esterified with ceramides, are mostly straight long-chain saturated compounds with a small polar head group and a high melting point. This means that at physiological temperature, the lipid chains are mostly in a solid crystalline or gel state. In these states, the membrane exhibits low lateral diffusional properties and is less permeable than the membrane in a liquid crystalline state, present at higher temperatures (figure 5). ${ }^{[37,68-71]}$

In the solid crystalline phase and, to a lesser extent, the gel phase, the lipids exhibit a long range order i.e. they display a specific orientation with respect to one another. Alkyl chains are in the alltrans configuration, which facilitates the interaction between adjacent chains and lateral diffusion of a lipid in the membrane is extremely slow. An increase in the number of gauche isomers is observed for the gel phase, promoting a slightly faster diffusion. In the liquid crystalline phase, many more alkyl chains are in the gauche configuration. They do not pack into specific arrangements, allowing rapid lateral mobility. ${ }^{[46]}$

Lipid-phase transitions in model membrane systems can be induced by changing the pressure, hydration, solvents, salt concentration, $\mathrm{pH}$, cations, temperature, and proteins. Lipid composition strongly influences the phase transition temperature. Increasing the alkyl chain length of a phospholipid by 2 carbons raises the gel-liquid phase transition temperature by $20^{\circ} \mathrm{C}$ whereas increasing the degree of unsaturation of the alkyl chain by the introduction of a double bond decreases it by as much as $35^{\circ} \mathrm{C}$. Cholesterol influences the gel-liquid crystalline phase transition by decreasing the enthalpy of the phase transition. ${ }^{[51]}$ Note that 


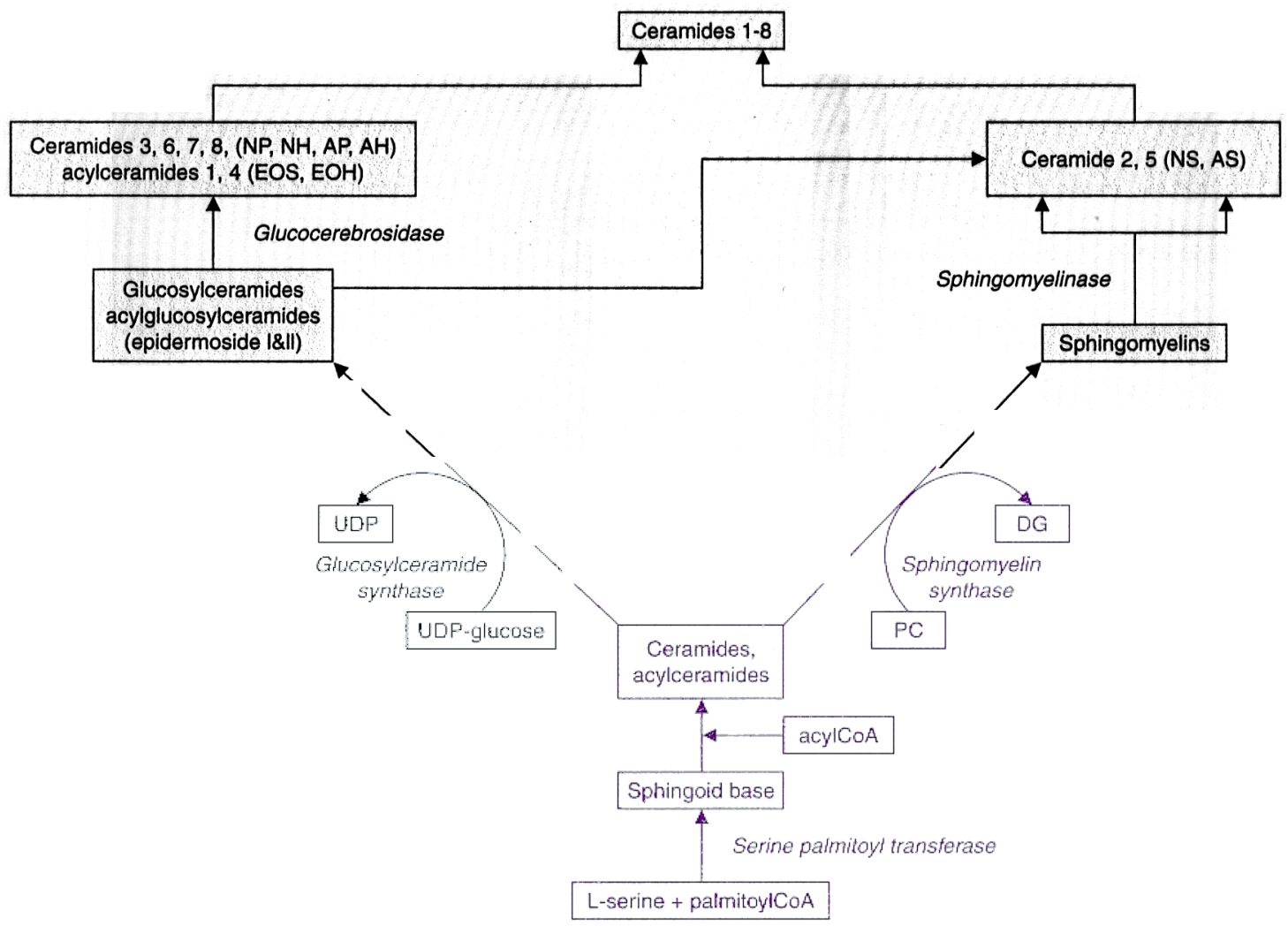

Fig. 4. Proposed pathway for the production of stratum corneum ceramides. The scheme for the production of the eight stratum corneum ceramides (Cer 1-Cer 8) distinguishes between glucosylceramide- and sphingomyelin-dependent pathways, and is based on the results presented by Uchida et al. ${ }^{\text {[43] }}$ (reproduced from Uchida et al. ${ }^{[43]}$ with permission). $\mathbf{A}=\alpha$-hydroxy acid; $\mathbf{C o A}=$ coenzyme $\mathrm{A} ; \mathbf{D G}=$ diacylglycerol; EO $=$ esterified $\omega$-hydroxy acid; $\mathbf{H}=$ 6-hydroxysphingosine; $\mathbf{N}=$ nonhydroxy acid; $\mathbf{P}=$ phytosphingosine; $\mathbf{P C}=$ phosphatidylcholine; $\mathbf{S}=$ sphingosine; UDP = uridine diphosphate.

the changes in composition of membranes are greater if they promote a change between different phases than if they remain within a single phase. For example, although increasing the saturation of the alkyl chains in a membrane will lead to an increase in the membrane order, the effect will be relatively small unless a phase transition is induced at physiological temperatures.

Thus, the phase-transition temperature for stratum corneum lipids, and particularly the ceramides, is higher than the physiological body temperature, preventing an excessively high fluidizing effect on intercellular membrane domains. The presence of unsaturated fatty acids is important in that it confers sufficient pliability to the lipid structure order to prevent cracks and, consequently, a reduced barrier function. In the domain mosaic model of Forslind, ${ }^{669-71]}$ it has been proposed that the intercellular lipid lamellae consist of gel-phase domains within a continuous liquidcrystalline area. Molecules crossing these multilamellar layers would penetrate more easily through the more fluid liquid-crystalline domains or at the phase boundaries (due to chain packing defects) than through the gel phase.

The lipid structure and organization of the skin barrier have been studied using a number of physical techniques including small- and wide-angle $X$-ray diffraction, ${ }^{[68,72-78]}$ electron diffraction, ${ }^{[76,79,80]}$ transmission and scanning freeze-fracture electron microscopy, ${ }^{[39,81-83]}$ nuclear magnetic resonance spectroscopy, ${ }^{[84,85}$ differential scanning calorimetry, ${ }^{[75,86]}$ atomic force microscopy ${ }^{[87,88]}$ and Fourier transform infrared spectroscopy. ${ }^{[89-93]}$

Analysis of the pattern of human stratum corneum with wideangle $\mathrm{X}$-ray diffraction distinguishes two rings at 0.37 and $0.41 \mathrm{~nm}$ spacing. ${ }^{[94]}$ These rings are attributed to the orthorhombic lateral packing. However, whether or not a hexagonal sublattice coexists with an orthorhombic sublattice cannot be deduced from the diffraction pattern since there is an overlapping of the reflection characteristics for both the hexagonal and the orthorhombic phases. For this reason lateral packing has recently been studied by electron diffraction using sequential strips of stratum corn- 
eum. ${ }^{[80]}$ With this approach it is evident that throughout the stratum corneum the lipids form an orthorhombic lattice with the exception of the most superficial layers in which hexagonal packing has, occasionally, been observed.

From the small-angle $\mathrm{X}$-ray diffraction pattern it appears that in stratum corneum two lamellar phases are present, one with a periodicity of approximately $6.4 \mathrm{~nm}$ and the other with a periodicity of approximately $13.4 \mathrm{~nm}$, respectively. ${ }^{[95]}$ Using ruthenium tetroxide post fixation, an unusual lipid bilayer arrangement has been found. The $13 \mathrm{~nm}$ thick lamellar structure consists of two electron translucent broad bands and one electron translucent narrow band (the so called Landmann units) which are not equal in width ${ }^{[39,72,77,81,83]}$ (see figure 6). Since the $13 \mathrm{~nm}$ lamellar phase has always been present in all species studied so far, this phase is considered to be important for the skin barrier function.

The important role of Cer 1 (EOS) in the formation of the $13.4 \mathrm{~nm}$ lamellar phase and in the transition from a hexagonal to an ortho- rhombic phase induced by free fatty acids has been observed in mixtures prepared with isolated stratum corneum lipids as well as in intact human stratum corneum. ${ }^{[76,96]}$ Lipid-phase behavior of mixtures of cholesterol, free fatty acids, and total ceramide fraction has been compared with that of mixtures of cholesterol, free fatty acids, and ceramide mixture lacking Cer 1 (EOS). These studies have shown that in the absence of Cer 1 (EOS) almost no long periodicity phase is formed. ${ }^{[76,96]}$ From these studies, a sandwich model has been proposed for the molecular arrangement of the two lamellar phases in which the different ceramides are allocated in the different layers (figure 7).

In this model, the lipids are organized into 3 layers. The two broad regions are formed by partly interdigitating ceramides with long-chain fatty acids of approximately 24-26 carbon atoms, while the narrow low-electron density regions are formed by fully interdigitating ceramides with a short fatty acid chain of approximately 16-18 carbon atoms. Furthermore, long Cer 1 (EOS) and

\section{Phase}

Structure

Crystalline (gel)

Liquid crystalline
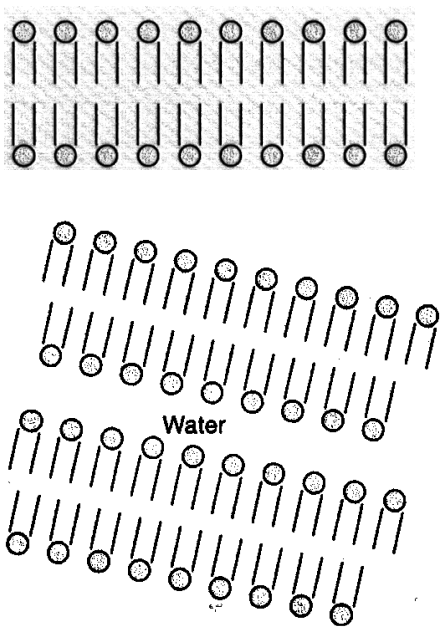

$\{9$

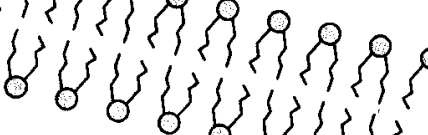

is

Water
Incidence of trans-gauche isomerization

All trans

Some gauche

Trans-gauche mixture
Diffusion coefficient $\left(\mathrm{cm}^{2} / \mathrm{sec}\right)$
$<10^{-14}$

$10^{-11}$

$10^{-8}$

Fig. 5. Schematic representation of three bilayer phases: solid, gel, and liquid crystalline. The degree of interaction is less in the gel and liquid crystalline phases. Characteristic chain-packing configurations, the degree of trans/gauche isomerization and lateral diffusion coefficients are also presented. These properties should be considered illustrative, rather than definitive (reproduced from Schaefer and Redelmeier, ${ }^{[46]}$ with permission). 
Cer $4(\mathrm{EOH})$ are important for the formation of this phase with the unsaturated linoleic acid moiety located in the central narrow layer of this model.

These findings reflect observations made in vivo comparing normal and diseased skin. For this purpose, the lipid-phase behavior of stratum corneum derived from healthy, dry skin and lamellar ichthyosis skin has been examined. Dry skin is selected because of its low Cer 1 (EOS) content ${ }^{[97]}$ and lamellar ichthyosis skin because of its low free fatty acid content. ${ }^{[98]}$ The lipid composition of the stratum corneum samples is examined and the mean content of Cer1 (EOS) and Cer 4 (EOH) determined. It appears that the absence of the $13 \mathrm{~nm}$ lamellar phase is in concert with a reduced content of these two ceramides. ${ }^{\text {[76] }}$

Fourier transform infrared spectroscopy yields information about the physical conformation of the lipid hydrocarbon chains, sensitive to the trans/gauche ratio, intramolecular order, the lateral hydrocarbon chain packing, intermolecular chain interactions and intermolecular hydrogen bonding between polar head groups. Differential scanning calorimetry registers the latent heat, or enthalpy difference $(\Delta \mathrm{H})$ between the two states at a phase transition. Infrared and differential scanning calorimetry of human stratum corneum demonstrate thermal phase transitions at 35,65 , 80 and $95^{\circ} \mathrm{C}^{[99-101]}$ (see figure 8 ). The transitions are relatively broad, reflecting a lack of cooperativity. The three lower transitions are assigned to the intercellular lipid component since they are altered after solvent extraction. The small transition close to $35^{\circ} \mathrm{C}$ is recorded and attributed to contamination by e.g. sebaceous lipids.

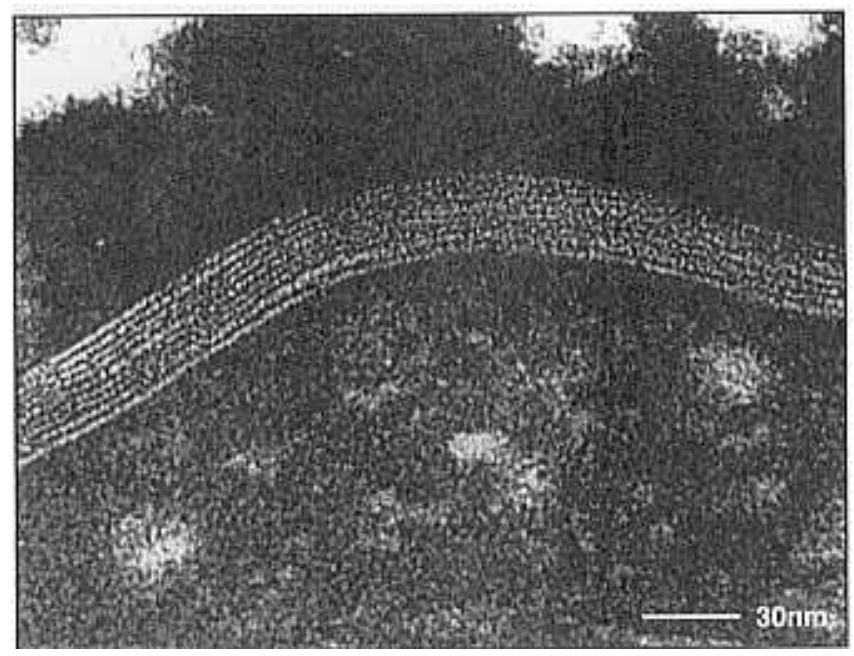

Fig. 6. Ruthenium tetroxide stained human stratum corneum. In the stratum corneum lipid regions, the lipid lamellar, broad-narrow-broad electron translucent bands are depicted (reproduced from López et al., ${ }^{[83]}$ with permission from Elsevier Science).

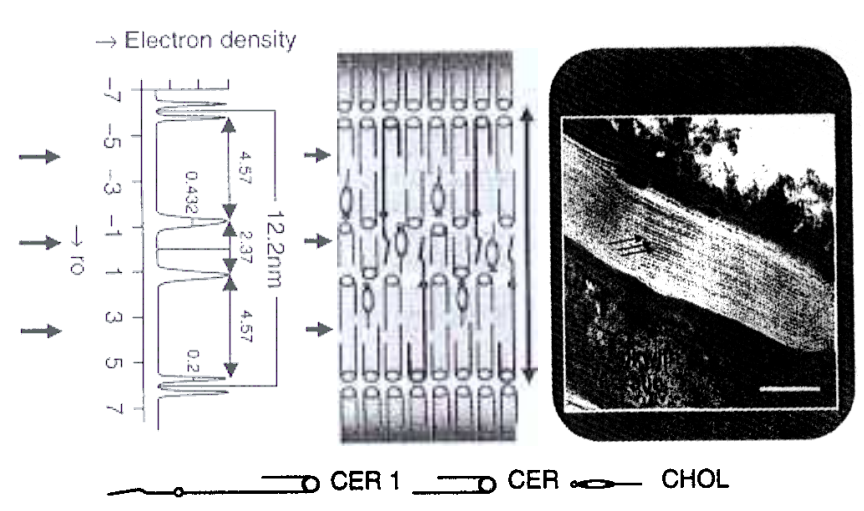

Fig. 7. The left-hand figure shows the electron density profile calculated from the peak intensities attributed to the $12.2 \mathrm{~nm}$ lamellar phase of the equimolar cholesterol:pig ceramide mixture. On the right-hand side the lamellar organization of ruthenium tetroxide-fixed stratum corneum with the broad-narrowbroad electron translucent band sequence is shown. Based on this sequence, a model is proposed with three lipid layers with a prominent role of ceramide (Cer) 1 (EOS). Furthermore, the unsaturated linoleic moiety of Cer 1 (EOS) and Cer 4 (EOH) are located in the central narrow layer of this model (reproduced from Bouwstra et al., ${ }^{[76]}$ with permission from Karger). $\mathrm{CHOL}=$ cholesterol.

However, recent studies have indicated a sharp increase in the proportion of gauche conformers along the hydrocarbon chains between 32 and $37^{\circ} \mathrm{C}$. This is attributed to the crystalline to liquid crystalline transformation of a subfraction of stratum corneum lipids. ${ }^{[102]}$ The $95^{\circ} \mathrm{C}$ transition is assigned to keratin denaturation since it is found after extraction of lipids by solvents and it is not thermally reversible. ${ }^{[46]}$ However, the presence of thermal transitions at these relatively high temperatures and their modification with hydration indicate that intercellular lipids have properties different from those of other biological membranes.

A study of structural and thermotropic properties of $\alpha$ hydroxy fatty acid-containing ceramides (ACers) [Cer 5, 7 or 8 , (AS, AP or AH)] and nonhydroxy fatty acid-containing ceramides (NCers) [Cer 2 or 3 (NS or NP)] using differential scanning colorimetry and $\mathrm{X}$-ray diffraction techniques demonstrates thermotropic behavior changes with hydration. ${ }^{[75]}$ ACers show a simple reversible thermal behavior involving conversion of a gel phase to a hexagonal phase $\left(\mathrm{L}_{\beta} \rightarrow \mathrm{H}_{11}\right)$, whereas the NCers show a more complex polymorphic phase behavior involving two gel phases. This study suggests that ceramide hydroxylation leads to increased intermolecular interactions which somehow inhibit formation of a stable state.

Fourier transform infrared spectroscopy studies are nowadays conducted with Cer 2 (NS) analogues of different specific chain lengths ${ }^{[92]}$ with the three possible equimolar binary mixtures of cholesterol, stearic acid and Cer $2(\mathrm{NS})^{[93]}$ and model stratum 
corneum ternary lipid mixtures of equimolar amounts of cholesterol, deuterated palmitic acid and Cer $2(\mathrm{NS})^{[89,90]}$ or Cer 5 (AS) ${ }^{[91]}$ or Cer 3 (NP) or Cer 7 (AP). ${ }^{[103]}$

As regards the Cer 2 (NS) in the ternary mixture, the ceramide fraction transition into an isotropic state occurs at approximately $50-75^{\circ} \mathrm{C}$, whereas the chain disorder of the palmitic acid phase begins at $42^{\circ} \mathrm{C}$ with a transition point of $50^{\circ} \mathrm{C}$. Cer 2 (NS) forms separate domains within these ternary stratum corneum models and the lipids do not collapse with the disordering of palmitic acid. ${ }^{[89,90]}$

In the Cer 5 (AS) model, the methylene stretching frequencies again provide evidence that palmitic acid and Cer 5 (AS) are fully extended all-trans conformations, tightly packed at physiological temperatures. However, both components have sharper phase transitions than the components of the Cer 2 (NS) model at the same temperature $\sim 50^{\circ} \mathrm{C}$. This suggests that there is less mixing with cholesterol and that the Cer 5 (AS) domains are probably fairly small and do not segregate from fatty acid domain in the skin barrier model. ${ }^{[91]}$

The phytosphingosine-based ceramides Cer 3 (NP) and Cer 7 (AP) exhibit phase behaviors that are markedly different from those of Cer 2 (NS) and Cer 5 (AS). The Cer 3 (NP) when combined with palmitic acid and cholesterol does not exhibit any phase transition up to temperatures above $90^{\circ} \mathrm{C}$, although the fatty acid and cholesterol appear to loosen the chain packing of Cer 3 (NP). However, Cer 7 (AP) in the model has a broad transition at $\sim 90^{\circ} \mathrm{C}$, suggesting some interaction between this Cer 7 (AP) and the other model stratum corneum components. ${ }^{[103]}$

These different physical properties have been determined by studying the $\mathrm{CH}_{2}$-stretching vibrations which illustrate the intramolecular conformational order of the lipid chains within the bilayer. Since cohesiveness of the stratum corneum lipid barrier is partly derived from intermolecular hydrogen bonding between groups, it has also been monitored in the same spectra as the chain interactions. The carbonyl stretching mode and ceramide amides I and II provide information on head group interactions in the stratum corneum models ${ }^{[103]}$ (see figure 9). The splitting in the amide I mode of Cer 2 (NS) suggests an intermolecular bonding between opposing Cer 2 (NS) head groups. In contrast, none of the other ceramide species demonstrate splitting in the amide modes. However, the lower frequencies observed for Cer 5 (AS) and $\mathrm{Cer} 7$ (AP) are indicative of strongly $\mathrm{H}$-bonded head groups. The small temperature dependence of the lowest amide I frequency of $\sim 1612 \mathrm{~cm}^{-1}$ for Cer 3 (NP) indicates a very strong internal H-bond. ${ }^{[103]}$

All these biophysical studies shed some light on the unusual properties of hydrated ceramides, and on how these properties relate to ceramide function in the stratum corneum. It is quite clear that the diversity of ceramides found in the stratum corneum does not reflect redundancy because each ceramide species has unique properties that contribute to stratum comeum organization and cohesion and thereby provide the stratum corneum with its barrier function.

\section{Relationship Between Ceramides and Barrier Function of Skin}

Studies using very simple membrane models, such as liposomes formed by stratum corneum lipid mixtures, have demonstrated the important role of the ceramides in the preservation of the permeability and integrity of the bilayer structures. ${ }^{[04]}$ Strong evidence that stratum corneum barrier lipids, especially ceramides, play a crucial role in the water retention capacity of the skin also comes from medical research of various skin disorders. ${ }^{[6,105]}$ Indeed, a variety of skin conditions and diseases are characterized by hyperkeratinization, often associated with redness and itching. The skin is dry and rough and shows an impaired lipid barrier and an increased trans-epidermal water loss.

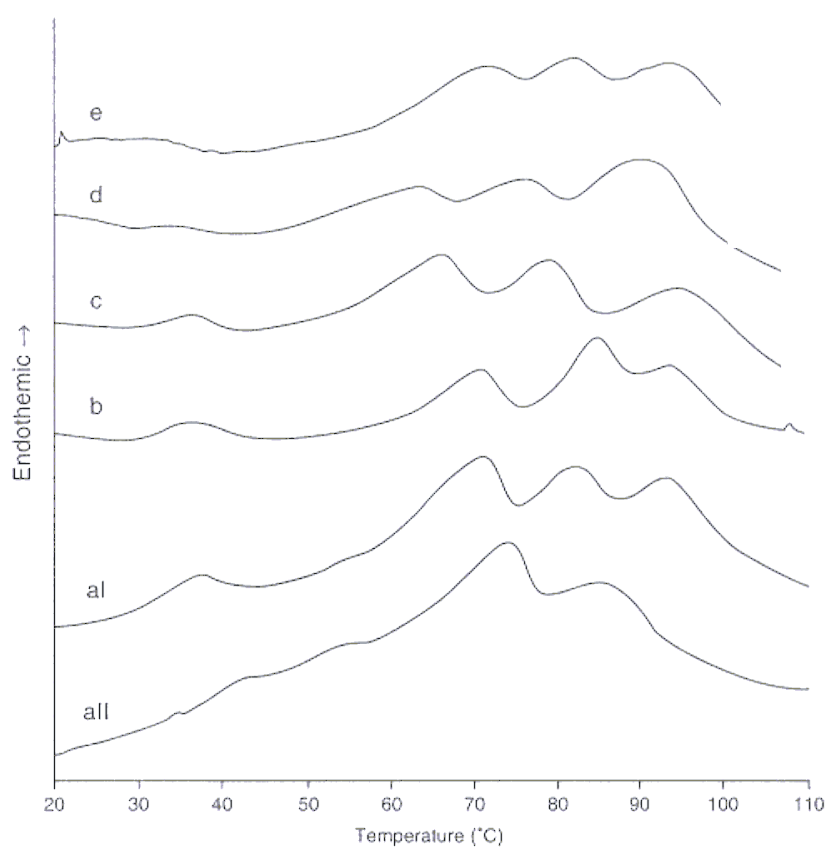

Fig. 8. Differential scanning calorimetry profiles of five human stratum corneum samples. Samples al (dry) and all (hydrated) were from the same source at the indicated hydration levels. The other samples were from different sources. A minor transition is observed at $37-40^{\circ} \mathrm{C}$; principle transitions attributed to intercellular lipid are observed at $68-70^{\circ} \mathrm{C}$ and $80^{\circ} \mathrm{C}$ with a small transition observed at $95^{\circ} \mathrm{C}$ in some samples (reproduced from Schaefer and Redelmeier, ${ }^{[46]}$ with permission from Karger). 


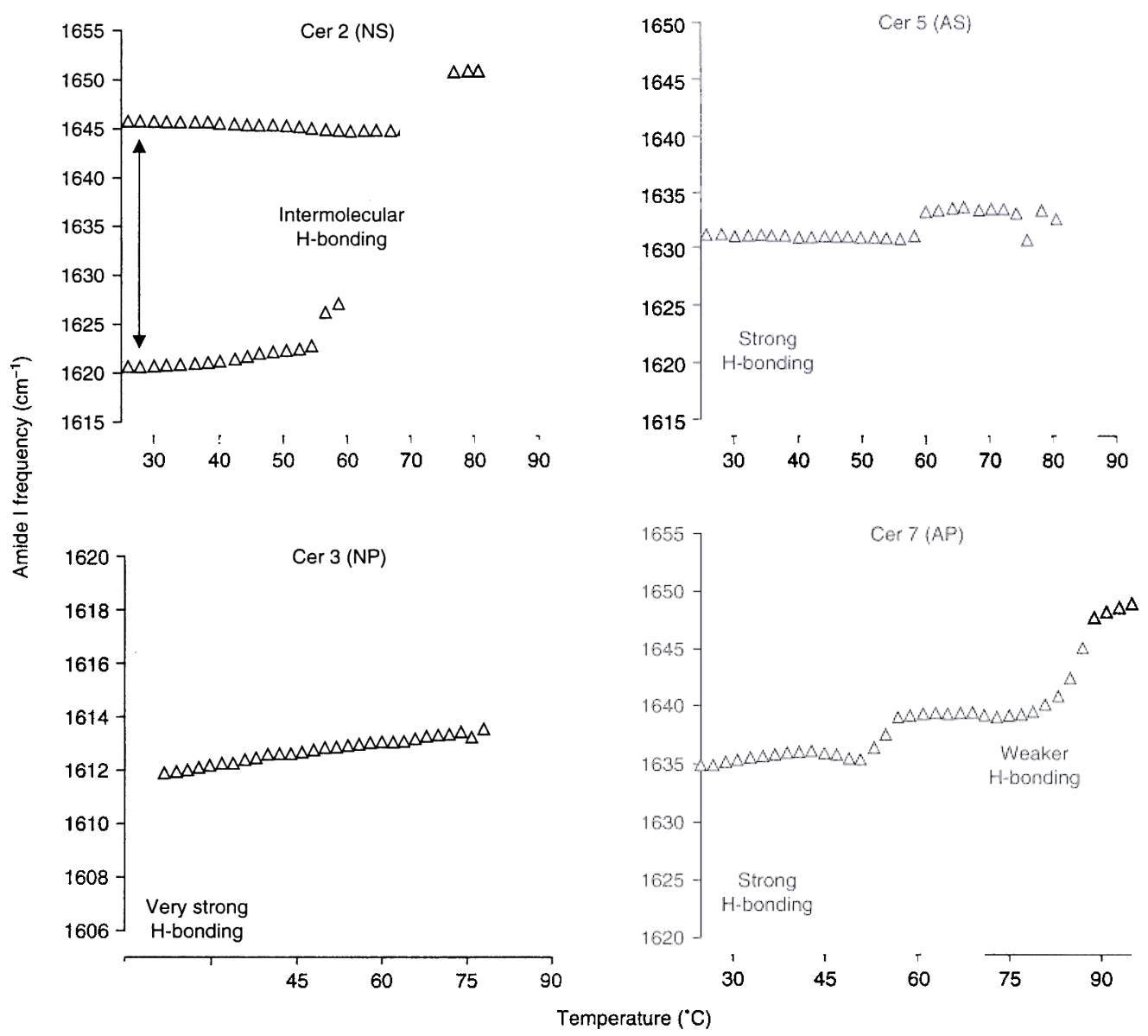

Fig. 9. The temperature dependence of the amide I mode of ceramide (Cer) 2 (NS), Cer 3 (NP), Cer 5 (AS) and Cer 7 (AP), in ternary lipid models of the skin barrier. This mode provides a direct measure of head-group $H$-bonding (reproduced from Moore and Rerek, ${ }^{[103]}$ with permission). $A=\alpha$-hydroxy acid; $\mathbf{N}=$ nonhydroxy acid; $\mathbf{P}=$ phytosphinogosine; $\mathbf{S}=$ sphingosine.

The following classification of skin barrier problems has been made. ${ }^{[106]}$

- Acute damage to the skin barrier, very common and normally not associated with inflammation leading to a skin pathology. Examples are extraction with organic solvents and short exposure to aggressive detergents.

- Chronic damage to the skin barrier as seen in xerosis, often season-linked and more common in persons with an atopic skin. Changes in the horny layer such as scaliness, roughness and abnormal dryness are important symptoms of barrier damage. These symptoms, as also observed in irritant contact dermatitis, lead to an inflammatory reaction and sometimes to the onset of skin diseases.

- Structural changes in the skin barrier as observed in ichthyosis, general dyskeratotic disorders and atopic skin.

- Inflammatory skin diseases accompanied by skin barrier changes; examples are atopic dermatitis and psoriasis.
The link between skin disorders and changes in barrier lipid composition is, however, difficult to prove because of the many variables that could play a crucial role in the regulation and modulation of the composition of the skin barrier including: [107]

- variables related to the individual such as age, sex, body site, and phenotype; [108-110]

- environmental variables including seasonal variations, UV light, and contamination of the extracted barrier lipids with sebaceous lipids; ${ }^{64,111,112]}$

- low amounts of the barrier lipids in damaged skin, requiring sensitive quantification techniques; ${ }^{[13]}$

- difficulties in the comparison of interlaboratory results. ${ }^{1108,110]}$

Bearing the above considerations in mind, a summary of the state-of-the-art relationship between the presence or composition of ceramides and barrier impairment in healthy or diseased skin is presented in the remainder of the section. 


\subsection{Effect of Anatomical Site, Sex, Age, and Season}

Barrier properties of different skin sites cannot be attributed to differences in thickness or the number of cell layers in stratum corneum. Rather, an inverse relationship exists between the lipid weight percentage and the permeability properties of a particular site, with significant regional differences in the lipid compositional profile. ${ }^{[108]}$ For example, despite the small amount of lipids, the proportion of ceramides and cholesterol is much higher in palmoplantar stratum corneum than on the extensor surfaces of extremities, abdominal or facial stratum corneum. However, the significance of these differences in lipid distribution is not known. Functional interpretations require consideration not only of lipid distribution and weight percentages, but also information about site-related variations in the fatty acid profiles of esterified species, and at present these data are not available.

These regional differences in lipid content do have important clinical implications. ${ }^{[40]}$ First, they correlate with susceptibility to the development of contact dermatitis to lipophilic antigens (e.g. poison ivy) or hydrophilic antigens (e.g. foods, flowers) at lipid-replete sites (e.g. face) or lipid-depleted sites (e.g. palms, soles). Second, individuals with atopic dermatitis who display a paucity of stratum corneum lipids are less readily sensitized to lipid soluble compounds than to hydrophilic antigens, such as nickel. Third, percutaneous drug delivery of lipid-soluble drugs, such as topical corticosteroids and retinoids, occurs more readily at lipid-replete sites. Finally, the low lipid content of palms and soles explains the increased susceptibility of these sites to the development of soap/surfactant- and hot water-induced dermatitis. Moreover, the distribution of lipids at nonkeratinized, oral mucosal sites, which generally have a higher water permeability than keratinized regions, is different from that in the epidermis. ${ }^{[114,115]}$ There is a replacement of ceramides and free fatty acids by glucosylceramides and phospholipids, respectively.

In some reports, changes in ceramides and total stratum corneum lipid content with increasing age have been described and it is now generally accepted that there is an overall decrease in total stratum corneum lipids by approximately $30 \%$ in the elderly. ${ }^{[97,109,116-118]}$ It has been suggested that the decrease in the total ceramide content in aged skin could be a result of an agerelated increase in the ceramidase activity, whereas the activity of $\beta$-glucocerebrosidase remains unchanged. ${ }^{[19]}$ According to Yamamura et al., ${ }^{[120]}$ however, a downregulation of sphingomyelinase activity is at the basis of the decline in ceramide concentrations. Moreover, low amounts of ceramides ${ }^{[120]}$ and abnormal lamellar bodies have also been observed in senile xerotic skin. ${ }^{[121]}$

The incidence of skin xerosis appears to be greater both with increasing age and during the harsher climatic conditions of the winter season. No seasonal changes have been observed in the stratum corneum lipid levels in Japanese patients, ${ }^{[122]}$ whereas a decrease has been reported in winter xerosis in Caucasian women. ${ }^{[18,123]}$ Stratum corneum lipid levels of three body sites examined (face, hand, leg) were dramatically depleted in winter compared with spring and summer. ${ }^{[18]}$ The relative levels of Cer 1 (EOS) lignocerate, heptadecanoate, and linoleate are also depleted in winter and aged skin whereas Cer 1 (EOS) oleate levels increase. ${ }^{[18]}$ The crucial role of essential fatty acids in stratum corneum function has been appreciated for decades. ${ }^{[124]}$ In essential fatty acid deficiency, the replacement of linoleate with oleate in Cer 1 (EOS) is associated with dramatic perturbations in the ultrastructure of the stratum corneum lipids and desquamatory abnormalities. ${ }^{[125]}$ Essential fatty acid insufficiency is also associated with other less serious conditions. For example, Cer 1 (EOS) linoleate levels are reduced in atopic dermatitis, ${ }^{[126]}$ acne, ${ }^{[57]}$ and dry skin. ${ }^{[127]}$

Although water loss from skin does not appear to alter with age or season, the decrease in the mass levels of intercellular lipids and the altered ratios of fatty acids esterified to Cer 1 (EOS) are likely to contribute to the increased susceptibility of aged skin to perturbation of barrier function and xerosis, particularly during the winter months. ${ }^{[118]}$ In a recent study, the relationship between stratum corneum lipid composition, $\mathrm{X}$-ray diffraction pattern and barrier characteristics of different healthy human skin types (normal, dry, and aged skin) has been reported. ${ }^{[28]}$ A deficiency in $\omega$-hydroxy acid-containing Cer 1 (EOS) and Cer 4 (EOH), and an increase in nonhydroxy acid-containing Cer 2 (NS) and $\alpha$ hydroxy acid-containing Cer 5 (AS), coincides with a lack of the $4.4 \mathrm{~nm}$ peak attributed to the long periodicity phase, which occurs predominantly in young, dry skin and in a few cases of aged and young normal skin.

Ceramide distribution changes related to age and sex have been reported ${ }^{[110]}$ and significant differences have been obtained between age groups in female individuals only. There is a significant increase in Cer 1 (EOS) and Cer 2 (NS) with a corresponding decrease in Cer 3 (NP) and Cer 7 (AP) from prepubertal age to adulthood in females. Thereafter, from young adult to elderly women, the ratio of Cer 2 (NS) to total sphingolipids decreases with age in contrast to Cer 3 (NP), which shows an increase. This suggests a significant influence of female hormones on the composition of stratum corneum ceramides.

\subsection{Effect of Barrier Damage Induced by External Factors}

Contact dermatitis is induced by exposure of the skin to external substances and challenges including, surfactants, solvents, chemicals, metals, UV light, and even plain water. ${ }^{[106]}$ Perturba- 
tion of the barrier lipids by the use of organic solvents or detergents or its removal by tape stripping leads to a significant increase in water loss through the upper layers of the skin, ${ }^{[129]}$ followed by a cascade of homeostatic responses in the epidermis ${ }^{[130]}$ (see figure 10).

After barrier perturbation, the early stage of repair (within 1 hour) is characterized by lamellar body excretion ${ }^{[38]}$ and an increase in fatty acid and cholesterol biosynthesis, ${ }^{[55]}$ followed by a delayed synthesis (3-6 hours) of epidermal sphingolipids. ${ }^{\text {[62] }}$ This is the result of an increased development and activity of lipid processing enzymes, as a result of increased DNA synthesis. ${ }^{[130]}$ These enzymes catalyze the rate-limiting steps of the biosynthesis of sphingolipids (serine palmitoyl transferase), cholesterol (hydroxymethylglutaryl coenzyme A [HMG CoA] reductase) and fatty acids (acetyl CoA carboxylase). Once the barrier recovery is completed, the enzyme activities gradually return to baseline levels and decreases in transepidermal water loss are observed. ${ }^{37,131-133]}$

In vitro experiments using the non-ionic surfactant octylglucoside have demonstrated its insignificant effect on the lamellar structure of stratum corneum lipids. ${ }^{[134]}$ On the other hand, the treatment of the skin with surfactants such as the anionic sodium lauryl sulfate induces significant increases in transepidermal water loss in vivo, with greater changes in stratum corneum lipid composition than in total lipid levels. Increases in free cholesterol, Cer 2 (NS) and Cer 4 (EOH) are observed, whereas the concentrations of cholesterol esters, long-chain fatty acids and Cer 3 (NP) decrease. ${ }^{[135,136]}$

The relationship between the initial ceramide content of stratum corneum and induced changes in barrier function has also been studied after sodium lauryl sulfate application. ${ }^{[137]}$ The correlation found between baseline Cer 1 (EOS) and Cer 7 (AP) and skin barrier impairment indicates that individuals with low levels of these ceramides are more prone to developing an irritant contact dermatitis following exposure to detergent.

There are few studies on in vivo human irritation caused by organic solvents. ${ }^{[138-142]}$ Grubauer et al. ${ }^{[142]}$ found that the selective extraction of nonpolar lipids causes only a slight increase in transepidermal water loss, while the elution of polar lipids produces a linear correlation between transepidermal water loss and the quantity of lipids removed. Di Nardo and coworkers ${ }^{[138]}$ re-

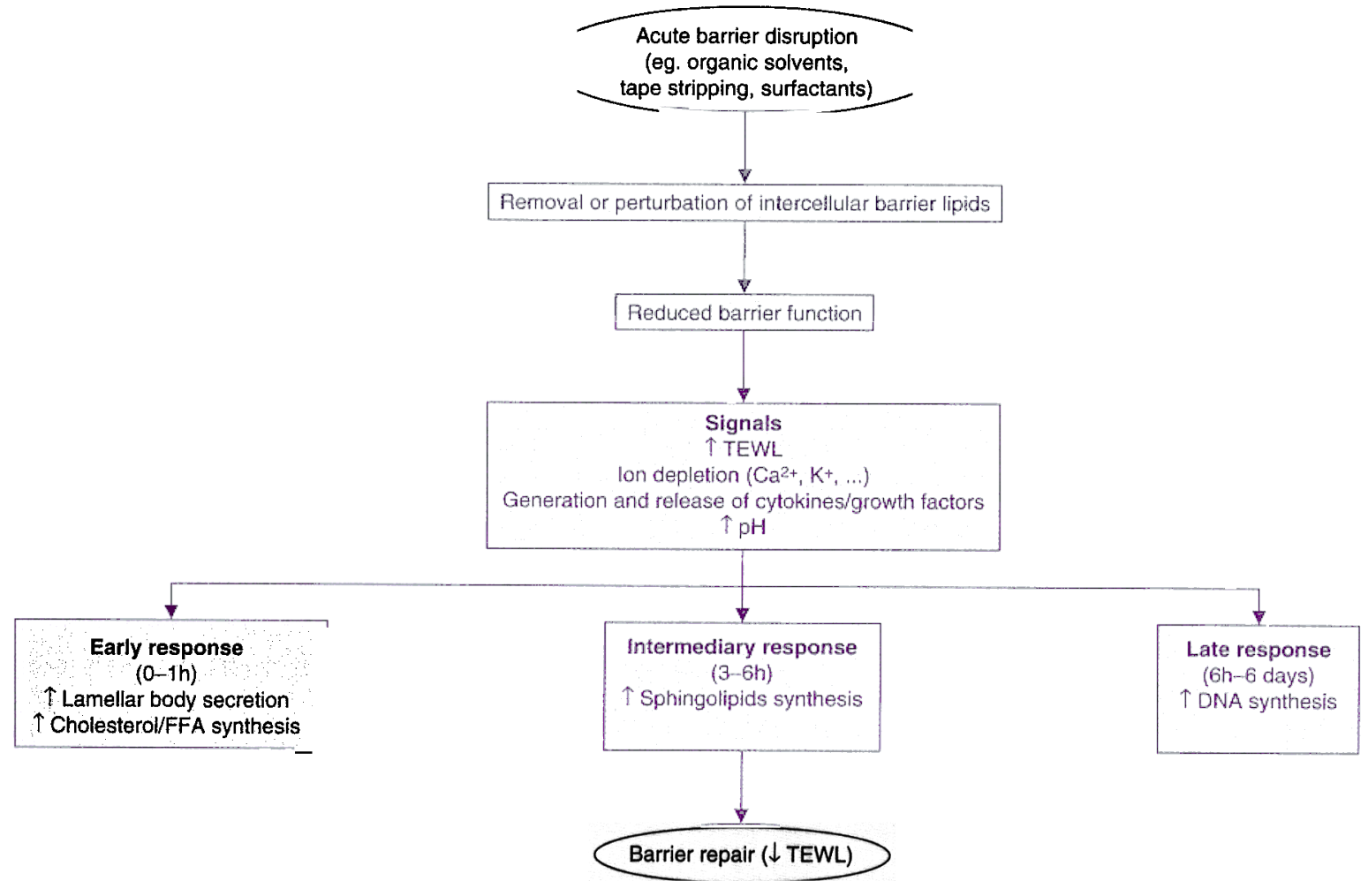

Fig. 10. Relationship between barrier disruption and signaling mechanisms followed by barrier repair. The absolute kinetics of these responses are speciesdependent and correlate with the degree of barrier perturbation (reproduced from De Paepe, ${ }^{[107]}$ with permission). FFA = free fatty acid; TEWL = transepidermal water loss; $\uparrow$ indicates increase in; $\downarrow$ indicates decrease in. 
ported irritant contact dermatitis caused by organic solvents such as toluene and xylene. The skin of many workers in the chemical and cosmetic industry is frequently exposed to organic solvents resulting in the sensitization of the skin. A significantly lower baseline total weight of ceramides has been reported in individuals showing the greatest tendency for irritation. The profile of single lipid classes in these individuals suggest that the impairment is directly related reduced levels of Cer 7, 5, 4, and 3 (AP, AS, EOH, and NP). ${ }^{[138]}$

Another external source of skin damage is UV irradiation, which may influence the composition of stratum corneum lipids and barrier function; however, whether the effect is harmful or beneficial depends of the UV dose. Provided that the irradiation occurs at suberythemal doses, increases in the amount of stratum corneum lipids and improvement in barrier function are observed. ${ }^{[111]}$ The ceramide fraction is especially enhanced, with the appearance of two new ceramide subfractions in the polar ceramide region following irradiation. This explains the beneficial effects of phototherapy on atopic skin. In the latter case, it has been reported that not only is lamellar body content extrusion improved, but also its conversion into lipid lamellae in the stratum corneum. ${ }^{[121]}$ However, high UV doses above the suberythemal level cause barrier damage characterized by inflammation and scaliness of the skin with concomitant increases in transepidermal water loss. ${ }^{[11]}$

\subsection{Pathological Skin Disorders}

A number of skin pathologies directly cause structural alterations in the stratum corneum as a result of malfunction of epidermal lipid metabolism, resulting in a loss of barrier function. In this respect, the most cited skin pathologies are psoriasis, ${ }^{[32,113,143-147]}$ atopic dermatitis, ${ }^{[146,148-154]}$ some forms of ichthyosis, ${ }^{\text {(98, 155-159] }}$ and severe xerosis. ${ }^{[123,128,160,161]}$

\subsection{Psoriasis}

Psoriasis is a hyperproliferative disease of the epidermis characterized by abnormal epidermal maturation leading to an incomplete process of differentiation with a consequently defective skin barrier function. An ultrastructural analysis of the stratum corneum of psoriatic lesions has revealed extremely narrow intercellular spaces, containing few pathological lipid lamellae, between a large number of parakeratotic corneocytes. ${ }^{[146]}$

These morphologic findings are consistent with biochemical studies that show a decrease in relative free fatty acid content and a different pattern in ceramide distribution in psoriatic plaques compared with normal control skin. ${ }^{[13,144]}$ In psoriatic skin, the phytosphingosine-carrying ceramides (Cer $3^{\circ}$ [NP] and Cer 7 [AP]) show a statistically significant decrease versus normal stra- tum corneum; some sphingosine-carrying ceramides (Cer 2 [NS]) and two new fractions with polarity similar to Cer 2 and 5 (this new Cer $5^{\prime}$ could be the recently found Cer $\left.6[\mathrm{NH}]\right)^{[60]}$ increase, whereas others (Cer 1 [EOS], Cer 4 [EOH] and Cer 5 [AS]) decrease. It has been postulated that the defect in skin barrier function may be attributed to Cer 1 and 4 (EOS and EOH) reduction since they are the main linoleate derivatives. Subsequent studies $^{[147,159]}$ have demonstrated the disturbances in the pathways of the ceramide generation. Propaposin, the precursor of saposins (sphingolipid activator proteins) and sphingomyelinase show a decrease in the stratum corneum of psoriatic lesional compared with nonlesional skin. ${ }^{[147]}$

\subsubsection{Afopic Dermatitis}

Atopic dermatitis skin tends to be easily irritated and appears to be dry. These clinical traits correspond to an impaired barrier function evidenced by an increase in transepidermal water loss values and a decrease in hydration values in patients with atopic dermatitis with eczematous or with apparently normal skin. ${ }^{[162,163]}$ Recent biochemical findings indicate that disturbances of epidermal lipid compartment structures, and particularly of ceramides, account for defects in barrier function of atopic dry skin. ${ }^{[149-154]}$ Compared with healthy skin, a decrease in the ceramide lipid fraction and a diminished ratio of ceramides and free sterols have been demonstrated in atopic dry skin. ${ }^{[149,150]}$ The total amount of ceramides in the lesional and non-lesional atopic skin also exhibits a similar and significant decrease compared with those of healthy individuals of the same age, Cer 1 (EOS) being the most significantly reduced in both cases. ${ }^{[151]}$ Other authors ${ }^{[152]}$ have found only a slightly lower proportion of ceramides in patients with atopic dermatitis. Only Cer 1 (EOS) is statistically decreased, showing an increase in its esterified oleic acid. Therefore, patients with atopic dermatitis have altered ceramide constituents so that the absolute amount of the linoleate is probably less than that of normal controls.

The relationship between epidermal lipids and barrier impairment in atopic dermatitis skin has been assessed by Di Nardo et al. ${ }^{[154]}$ Patients with active signs of eczema have higher transepidermal water loss values and lower capacitance values than patients with no active signs of atopic dermatitis who have a normal barrier function. The levels of Cer 1, and 3 (EOS and NP) are significantly lower and the values of cholesterol significantly higher for all patients with atopic dermatitis, being much more pronounced for patients with active lesions. The quantity of Cer 3 (NP) is significantly correlated with transepidermal water loss. A recent work ${ }^{[164]}$ has confirmed this for the dry skin of patients with atopic dermatitis but not for patients with atopic dermatitis but normal-appearing skin. 
Additionally, sphingomyelin metabolism has been found to be altered in the skin of patients with atopic dermatitis when compared with normal skin. ${ }^{[153]}$ The sphingomyelin hydrolysis detected in patients with atopic dermatitis is attributable not to sphingomyelinase, which degrades sphingomyelin to yield ceramides and phosphorylcholine, but rather to a hitherto undiscovered epidermal enzyme sphingomyelin acylase, which releases free fatty acid and sphingosyl-phosphorylcholine instead of ceramides. All these findings suggest that sphingomyelin metabolism is altered in patients with atopic dermatitis, resulting in a decrease in the levels of ceramides, which could be an etiologic factor in the continuous generation of atopic dry and barrier disrupted skin observed in these patients.

\subsubsection{Ichthyosis}

Ichthyosis comprises a wide group of inherited and acquired 'retention hyperkeratosis' characterized by thickened and scaly stratum corneum. Despite its dry appearance, it does not necessarily correlate with a reduced water content. Ichthyosis can be related either to a reduced rate of corneocyte shedding (ichthyosis vulgaris and $\mathrm{X}$-linked recessive ichthyosis) or an increased rate of keratinocyte proliferation (lamellar ichthyosis, ichthyosis brittle hair syndrome, congenital ichthyosis form erythroderma and type II Gaucher's disease) and, in some cases, abnormality in lipid and ceramides metabolism is described. In contrast with the other ichthyotic states, patients with X-linked recessive ichthyosis show excessively high levels of cholesterol sulphate in the stratum corneum because of a deficiency of the enzyme steroid sulfatase. ${ }^{[155]}$ Although the stratum corneum lipid profiles in other ichthyotic diseases have not been fully determined, reduced levels of sphingosine have been found in a variety of individuals with various ichthyosis. ${ }^{[156]}$ In lamellar ichthyosis, the ceramide content of the intercellular lipid is altered and the ratio of free fatty acid : cholesterol or free fatty acid : ceramide is significantly decreased ${ }^{[98]}$ The differences in ceramide composition (lower amount of Cer 5 [AS] and higher amount of Cer 2 [NS] in ichthyotic patients) could explain the smaller spacing of lipid lamellae in ichthyotic skin. ${ }^{[98,165]}$ The reduction in acid sphingomyelinase activity found in congenital ichthyosis epidermolytic hyperkeratosis could account for the decreased ratio of ceramides versus the total lipids. ${ }^{[159]}$ Furthermore, Gaucher's disease is characterized by a deficiency in endogenous $\beta$-glucocerebrosidase activity leading to a high percentage of glucosylceramides (48-69\% of total glycolipids) and to the complete absence of ceramides in the stratum corneum. ${ }^{[158]}$

\subsubsection{Xerosis}

Xerosis is an example of a chronic skin barrier damage that is often season-linked and more common in persons with an atopic skin. Changes in the horny layer such as roughness and abnormal dryness are responsible for an increased susceptibility to irritants and consequent barrier damage. ${ }^{[166]}$ In severe xerotic skin, the replacement of the normal lipid bilayer structure by large amounts of disorganized intercellular lipids in the upper layers of the stratum corneum has been detected. ${ }^{[123]}$ In addition the relative ceramide levels are decreased. Winter dry skin, which is also called xerosis, is a scaly, rough skin characterized by dryness and often by itching. Only small changes in total stratum corneum lipid concentrations have been reported and no correlation has been found between either cholesterol sulfate or ceramide and the degree of non-eczematous dry skin. ${ }^{[16,160,161]}$ However, in more recent reports a reduction in ceramides, and especially in Cer 1 (EOS) esterified with linoleate has been demonstrated in winter months with respect to the summer period ${ }^{[12,118]}$ (see section 4.1.)

\subsubsection{Acne}

Linoleate deficiency may also be an important factor in comedogenesis and, therefore, in the etiology of acne. ${ }^{[167]}$ No significant differences between acne and control individuals have been reported with regards to ceramide proportions from the skin surface, but the proportions of Cer 1 and 2 (EOS and NS) are greater in comedonal lipids than in the leg surface lipids whereas the opposite is true for Cer 4/5 and 7 (EOH, AS and AP). ${ }^{[168]}$ Furthermore, comedonal acyl Cer 1 (EOS) contains considerably less linoleate than acyl Cer 1 (EOS) of skin surface, which is also decreased in patients with acne. ${ }^{[57,168]}$

\subsection{Summarv}

Despite all the different results published and the difficulties discussed above in the analysis of the ceramides, this section demonstrates the influence of a decrease in the total amount of ceramides and an impairment of the normal pattern of the different types of ceramides in several skin disorders, which can be summarized in table II. Whereas UV irradiation at suberythemal doses leads to an improvement in the barrier function with a special increase in ceramide fraction, most of the other skin disorders shown in table II that have a diminished barrier function present a decrease in the total ceramide content with arguable differences in the ceramide pattern. In many cases, the decrease in acyl Cer 1 (EOS) has been detected with a diminished content in the esterified linoleate and an increased content in esterified oleate.

\section{Ceramide Supplementation in Skin Disorders}

Over the past decade, it has been demonstrated that formulations containing lipids identical to those in skin and, in partic- 
Table II. Reported impairment of ceramides in skin disorders

\begin{tabular}{|c|c|c|c|}
\hline Skin disorder & $\begin{array}{l}\text { Total } \\
\text { ceramides }\end{array}$ & Ceramide pattern modification & Enzymatic cause \\
\hline \multirow[t]{2}{*}{ Aged skin } & $\downarrow$ & $\downarrow$ Cer 1 (EOS) and linoleate in Cer 1 (EOS) & $\uparrow$ Ceramidase activitv \\
\hline & & $\uparrow$ Oleate in Cer 1 (EOS) & \\
\hline \multirow[t]{2}{*}{ Winter xerosis } & & $\downarrow$ Linoleate in Cer 1 (EOS) & \\
\hline & & $\uparrow$ Oleate in Cer 1 (EOS) & \\
\hline \multirow[t]{2}{*}{ Surfactant-induced contact dermatitis } & & $\downarrow$ Cer 1 (EOS), Cer 3 (NP), Cer 7 (AP) & \\
\hline & & $\uparrow \operatorname{Cer} 2$ (NS), Cer $4(\mathrm{EOH})$ & \\
\hline Organic solvent-induced contact dermatitis & $\downarrow$ & $\downarrow$ Cer 3 (NP), Cer $4(E O H), \operatorname{Cer} 5$ (AS), Cer 7 (AP) & \\
\hline \multirow[t]{2}{*}{ Psoriasis } & & $\begin{array}{l}\downarrow \operatorname{Cer} 1 \text { (EOS), Cer } 3 \text { (NP), Cer } 4 \text { (EOH), Cer } 5 \text { (AS), } \\
\text { Cer } 7 \text { (AP) }\end{array}$ & $\downarrow$ Sphingomyelinase \\
\hline & & $\uparrow$ Cer 2 (NS) and new Cer $2^{\prime}$ and Cer $5^{\prime}$ & \\
\hline \multirow[t]{2}{*}{ Atopic dermatitis } & $\downarrow$ & $\downarrow$ Cer 1 (EOS), Cer 3 (NP), linoleate in Cer 1 (EOS) & $\uparrow$ Sphingomyelin acylase \\
\hline & & $\uparrow$ Oleate in Cer 1 (EOS) & \\
\hline \multirow[t]{2}{*}{ Lamellar ichthyosis } & $\downarrow$ & $\downarrow \operatorname{Cer} 5$ (AS) & \\
\hline & & $\uparrow$ Cer 2 (NS) & \\
\hline Congenital ichthyosis epidermolytic hyperkeratosis & $\downarrow$ & & $\downarrow$ Acid sphingomyelinase activity \\
\hline Gaucher's disease & $\downarrow$ & & $\downarrow \beta$-Glucocerebrosidase \\
\hline Arne & & $\downarrow$ Linoleate in Cer 1 (EOS) & \\
\hline
\end{tabular}

ular, some ceramide supplementation may improve disturbed skin conditions. Replenishment of endogenous stratum corneum lipids normalize or accelerate barrier recovery when applied to solventtreated, stripped, or surfactant-treated skin. ${ }^{[67,169-175]}$ The barrier lipids, cholesterol and fatty acids are valuable components of skin care products, but in the case of ceramides, the results published to date are less clear. ${ }^{[176]}$

Imokawa's group studied the effect of the topical application of sebaceous-rich lipids and stratum corneum lipids on lipiddepleted forearm skin that had been pretreated with acetone/ ether ${ }^{[177]}$ or with surfactant-treated dry skin. ${ }^{[63]}$ In both cases, only applications of the stratum corneum lipids caused a significant recovery in either conductance value or scaling, the ceramide fraction being the one that induced the highest increase in conductance. Furthermore, some synthetic pseudoceramides (long chain acyl amides of $\mathrm{OH}$-functional ethers) have been demonstrated to alleviate dry skin. ${ }^{[178]}$

It has also been demonstrated that when cholesterol, free fatty acids, ceramides, or even acylceramides are applied alone to solvent-perturbed skin, ${ }^{[170-172]}$ to stripped skin, ${ }^{[171]}$ and to some surfactant-treated skin ${ }^{[171]}$ they aggravate rather than improve the barrier. Likewise, any two-component system of the three key stratum corneum lipids is deleterious. In contrast, three-component mixtures of the three key lipids ${ }^{[170-172]}$ or two-component mixtures of acylceramides and cholesterol ${ }^{[172]}$ allow normal barrier recovery and can even accelerate barrier recovery, depending on the final proportion of the key lipids. The aggravation and amelioration mechanism of the barrier function resulting from the topical application of physiological lipids is the same: the lipids are quickly absorbed into the nucleated cell layers, and incorporated into nascent lamellar bodies. It has been suggested that whereas complete mixtures result in normal lamellar bodies and intercellular bilayers, incomplete mixtures yield abnormal lamellar body contents and disorder intercellular lamellae. ${ }^{[40]}$

Berardesca et al. ${ }^{[169]}$ have demonstrated that treatment with Cer 1 (EOS) fortifies the skin barrier against minor sodium lauryl sulfate-induced damage. Lintner et al. ${ }^{[174]}$ applied a synthetic Cer type 2 ( $\mathrm{N}$-stearoyl-DL-erytro-sphinganine) in an emulsion and showed a repairing effect on sodium lauryl sulfate-insulted skin and a barrier reinforcing effect on stripping-insulted skin. De Paepe et al. ${ }^{[176,179]}$ did not find any improvement in transepidermal water loss of aged and sodium lauryl sulfate-damaged skin after treatment with body lotions enriched in $\mathrm{Cer} 3 \mathrm{~b}$ (N-oleoyl-P). However, when a mixture of Cer 3, 3b and 7 (NP, N-oleoyl-P, AP) and other skin lipids were added to the control lotion, there was considerable improvement in barrier repair. ${ }^{[180]}$

Ceramides have also been topically applied structured as liposomes, which mimics the organized lipid structures of the stratum corneum. ${ }^{[181-185]}$ Again, although liposomal formulations containing only one kind of ceramide (Cer $3 \mathrm{~b}$ or $\mathrm{Cer} 7$ [N-oleoyl$P$ or AP]) do not clearly demonstrate a protective effect against sodium lauryl sulfate, ${ }^{[181]}$ promising results have been obtained 
with liposomes with a mixture of ceramides. ${ }^{[183-185]}$ The beneficial effect of liposomes with ceramides extracted from another keratinized tissue, such as wool fiber, on intact skin in aging populations or in people with dry skin has been reported. ${ }^{[184]}$ The ability to accelerate repair in stripped and sodium lauryl sulfatedisturbed skin has also been demonstrated in vivo. ${ }^{[183]}$ Additionally, the repairing effect of liposomes formed with stratum corneum lipids in delipidized skin has been confirmed in in vitro experiments. ${ }^{[175]}$ Pharmacological action of lipids isolated from other natural sources have been tested on UVB light-disrupted skin and again a higher turnover of the skin barrier is found when they are structured as liposomes. [185]

The utilization of physiological lipids according to these parameters envisages new forms of topical therapy for dermatoses. Some authors have expressed their wish to apply ceramides on different types of pathological skin. ${ }^{[158,172]}$ In fact, the topical application of stratum corneum lipid liposomes in patients with atopic eczema has been postulated to be effective in restoring the barrier function ${ }^{[186]}$ and in the delivery of active components. ${ }^{[187]}$ A recent work reported very promising results of a phase 1 trial of a ceramide-dominant, barrier repair moisturizer in childhood atopic dermatitis. ${ }^{[188]}$ Even though there are many patents with ceramide-containing formulations, to our knowledge, few works have been published demonstrating the therapeutical usefulness of ceramide formulations in the clinical arena. This could be because of the lack of commercially available ceramides of sufficient quantity and purity. Besides, there is as yet no clear information on the activity of each ceramide group, although a lot of work is currently being performed. ${ }^{448,76,88,92,93,103,128]}$

\section{Enhanced Ceramide Synthesis in Skin Disorders Through Delivery of Precursors}

An alternative to improving barrier function by topical application of the various mature lipid species is to enhance the natural lipid-synthetic capability of the epidermis through the topical delivery of lipid precursors. The earliest work in this field relates to the alleviation of essential fatty acid deficiency in humans. Topical application of formulations containing linoleic acid in the form of natural oils ${ }^{[189]}$ leads to enhanced synthesis of Cer 1 (EOS) linoleate and subsequent normalization of the linoleate/oleate ratio, which is modified in many skin diseases. Direct topical application of linoleic acid has also been shown to alleviate the symptoms of dry skin. ${ }^{[12]}$ Topically applied lactic acid, especially the L-isomer can function as a general precursor to ceramides. ${ }^{[190,191]}$

Other precursors such as serine, the primary substrate for serine palmitoyl transferase (figure 4) that is the rate-limiting enzyme in the ceramide biosynthesis pathway, are utilized by keratinocytes in the presence of thiols (lipoic acid and $\mathrm{N}$-acetylcysteine) to stimulate ceramide biosynthesis. ${ }^{[192]}$ These thiols presumably activate serine palmitoyl transferase by thiol disulphide exchange mechanisms, and might be expected to enhance barrier performance in damaged skin.

An alternative approach is to provide substrates that can feed into the biosynthetic pathways beyond the rate-limiting step. A good example is tetra-acetylphytosphingosine, a modified sphingoid base, which has been shown to stimulate ceramide biosynthesis in cultured keratinocytes. ${ }^{[193]}$ In subsequent clinical evaluation, topically applied tetra-acetylphytosphingosine increased the resistance of skin to surfactant damage. ${ }^{[194]}$ A synergistic improvement in stratum corneum ceramide levels and a corresponding increase in barrier function was achieved when tetra-acetylphytosphingosine was combined with $\omega$-hydroxy acids and linoleic acid. This triple lipid combination preferentially increases Cer 1 (EOS) levels. ${ }^{[194]}$

Ceramides and other sphingolipids are known to be involved in cellular decisions regarding differentiation and apoptosis. ${ }^{[195-197]}$ Hence, exogenously added ceramides may play an important prodifferentiation role, aiding barrier recovery. For example, exogenously supplied short-chain ceramides induce keratinocyte differentiation in vitro and short-chain ceramides and pseudoceramides also reinforce the pro-differentiation effects of vitamin D. ${ }^{[198]}$ Indeed vitamin $D$ is known to activate keratinocyte sphingomyelinase, leading to increased intracellular levels of ceramides. ${ }^{[199]}$ Furthermore, the topical application of nicotinamide (one of the B vitamins) has recently been shown to stimulate de novo synthesis of ceramides, with upregulation of serine palmytoyl transferase and other intercellular lipids of the stratum corneum. ${ }^{[200]}$ A key role of vitamin $\mathrm{C}$ in the formation of glucosylceramides and the most polar ceramides Cer 7 and 8 (AP and AH) was also demonstrated. ${ }^{[201]}$

The glycosylated ceramides have been reported to have both proliferative ${ }^{[202]}$ and differentiation-enhancing ${ }^{[203]}$ properties, and long-chain barrier ceramides have pro-differentiation activity in cultured keratinocytes. Indeed, Cer $1 \omega$-esterified fatty acid variants have been shown to have differing potencies in enhancing keratinocyte differentiation, with Cer 1-linoleate being the most potent form. ${ }^{[204]}$ Such observations raise the question as to whether the topical application of long-chain ceramides can, in addition to a direct, physical effect on barrier function, also have an impact on the underlying proliferation/differentiation responses of the epidermis. Indeed, this raises the issue of whether the intrinsic ceramide molecules have such functionality. However, given their extremely hydrophobic nature, it is considered unlikely that topically applied long-chain ceramides can penetrate through intact stratum corneum to influence the underlying epidermis. ${ }^{[205]}$ 


\section{Conclusion}

Research into the structure and function of the ceramides has increased substantially over the last two decades. Ceramides comprise a heterogeneous complex family of compounds of sphingoid bases of different alkyl chain length amide-linked with different fatty acids. It is generally recognized and supported by numerous studies that ceramides play an essential role in structuring and maintaining the water permeability barrier function of the skin. It is evident that the diversity of ceramides found in the stratum corneum does not reflect redundancy because each ceramide species has unique properties that contribute to stratum corneum organization and cohesion and thereby provide the stratum corneum with its barrier function.

Whereas UV irradiation at suberythemal doses leads to an improvement in barrier function with a marked increase in ceramide fraction, most skin disorders that have a diminished barrier function show a decrease in total ceramide content with some differences in the ceramide pattern. In many cases, a decrease in acyl Cer 1 (EOS) is detected with a diminished content of the esterified linoleate and an increased content of esterified oleate.

The lack of commercial availability of skin-identical ceramides at a reasonable cost also continues to be a problem. Admittedly, existing in vitro data, some animal studies and limited human data support potential benefits for use of ceramides in human skin care. However, these benefits will remain unexploited unless more extensive and critical data can show that ceramides or their natural precursors deliver clinical and consumer-perceived skin benefits.

\section{Acknowledgements}

We thank Ms C. Alonso, Dr M. Martí, and Mr G. von Knorring for their expert technical assistance. We are also indebted to Dr J. Notario (MD) and Professor J. Peiry (MD) from Servicio de Dermatología de la Ciudad Sanitaria y Universitaria de Bellvitge (Barcelona, Spain) for their useful comments.

No sources of funding were used to assist in the preparation of this manuscript. The authors have no conflicts of interest that are directly relevant to the content of this manuscript.

\section{References}

1. Roseman $\mathrm{S}$. The synthesis of complex carbohydrates by multiglycotransferease systems and their potential function in intercellular adhesion. Chem Phys Lipids 1970; 5: 270-97

2. Rapport MM, Graf L. Inmunochemical reactions of lipids. Prog Allergy 1969; 13 273-331

3. Harouse JM, Bhat S, Spitalnik SL, et al. Inhibition of entry of HIV-1 in neutral cell lines by antibodies against galactosyl ceramide. Science 1992; 253: 320-2

4. Nilsson G. Carbohydrate antigens in human lung carcinoma. APMIS Suppl 1992; 27: 149-61

5. Saito $\mathrm{T}$, Ochiai $\mathrm{H}$. Evidence for a glycolipid anchor of gp64, a putative cell-cel adhesion protein of Polysphondylium pallidum. Eur J Biochem 1993; 218: 623-8

6. Wiegandt H. Insect glycolipids. Biochim Biophys Acta 1992; 1123: 117-26

7. Curatolo $W$. Thermal behavior of fractionated and unfractionated bovine brain cerebrosides. Biochemistry $1982 ; 21: 1761-72$
8. Hoekstra D, Kok JW. Trafficking of glycosphingolipids in eukaryotic cells: sorting and recycling of lipids. Biochim Biophys Acta 1992; 1113: 277-94

9. Jeckel $D$, Karrenbauer $A$, Birk $R$, et al. Glucosylceramide is synthesized at the cytosolic surface of various Golgi subfractions. FEBS Lett 1990; 261: 155-7

10. Schutze SW, Potthof K, Machleidt T, et al. TNF activates NF- $K B$ by phosphatidylcholine-specific phospholipase C-induced "acidic" sphingomyelin breakdown. Cell 1992; 71: 765-76

11. Kim MY, Linardic C, Obeid L, et al. Identification of sphingomyelin turnover as an effector mechanism for the action of tumor necrosis factor alpha and gammainterferon. J Biol Chem 1991; 266: 484-9

12. Okazaki T, Bell RM, Hannun YA. Sphingomyelin turnover induced by vitamin D3 in HL-60 cells: role in cell differentiation. 1989; 264: 19076-80

13. Okazaki T, Bielawaski A, Bell RM, et al. Role of ceramide as lipid mediator of $1 \alpha$, 25-dihydroxyvitamin D3-induced HL-60 cell differentiation. J Biol Chem 1990; 265: 15823-31

14. Dobrowski RT, Hannun YA. Ceramide activates a cytosolic phosphatase. J Biol Chem 1992; 267: 5048-51

15. Goldkorn T, Dressler KA, Muindi J, et al. Ceramide stimulates epidermal growth factor receptor phosphorylation in A431 human epidermoid carcinoma cells: evidence that ceramide may mediate sphingosine action. J Biol Chem 1991; 266: 16092-7

16. Obeid LM, Linardic CM, Karolak LA, et al. Programmed cell death induced by ceramide. Science 1993; 259: 1769-71

17. Kalen A, Borchardt RA, Bell RM. Elevated ceramide levels in $\mathrm{GH} 4 \mathrm{Cl}$ cells treated with retinoic acid. Biochim Biophys Acta 1992; 1125: 90-6

18. Pagano RE. The Golgi apparatus: insights from lipid biochemistry. Biochem Soc Trans 1990; 18: 361-6

19. Rosenwald AG, Pagano RE. Inhibition of glycoprotein traffic through the secretory pathway by ceramide. J Biol Chem 1993; $268: 4577-9$

20. Joseph CK, Byun HS, Bittman R, et al. Substrate recognition by ceramide-activated protein kinase. J Biol Chem 1993; 268: 20002-6

21. Raines MA, Kolesnick RN, Golde DW. Sphingomyelinase and ceramide activate mitogen-activated protein-kinase. J Biol Chem 1993; 268: 14572-5

22. Dobrowsky RT, Hannun YA. Ceramide-activated protein phosphatase: partial purification and relationship to protein phosphatase 2 A. Adv Lipid Res 1993; 25: 91-104

23. Dobrowsky RT, Kamibayashi C, Mumby MC, et al. Ceramide activates heterotrimetric protein phosphatase 2 A. J Biol Chem 1993; 268: 15523-30

24. Geilen CC, Barz S, Bektas M. Sphingolipid signaling in epidermal homeostasis. Skin Pharmacol Appl Skin Physiol 2001; 14: 261-71

25. Elias PM, Friend DS. The permeability barrier in mammalian epidermis. J Cell Biol 1975; 65: 180-91

26. Elias PM, Goerke J, Friend DS. Mammalian epidermal barrier lipid layers: composition and influence on structure. J Invest Dermatol 1977; 69: 535-46

27. Elias PM. Epidermal lipids, barrier function, and desquamation. J Invest Dermato 1983; 80: 44-9

28. Landmann L. The epidermal permeability barrier. Anat Embryol (Berl) 1988; 178 $1-10$

29. Swartzenruber DC, Wertz PW, Madison KC, et al. Evidence that the corneocyte has a chemically bound lipid envelope. J Invest Dermatol 1987; 88: 709-13

30. Wertz PW, Downing DT. Covalently bound $\omega$-hydroxyacylsphingosine in the stratum corneum. Biochim Biophys Acta 1987; 917: 108-11

31. Steven AC, Steinert PM. Protein composition of cornified cell envelopes of epidermal keratinocytes. J Cell Sci 1994; 107: 693-700

32. Elias PM, Menon GK. Structural and lipid biochemical correlates of the epidermal permeability barrier. Adv Lipid Res 1991; 24: 1-26

33. Friberg SE, Kayali I, Rhein LD, et al. The importance of lipids for water uptake in stratum corneum. Int J Cosmet Sci 1990; 12: 5-12

34. Schürer NY, Plewig G, Elias PM. Stratum corneum lipid function. Dermatologica 1991; 183: 77-94

35. Fartasch $M$. The nature of the epidermal barrier: structural aspects. Adv Drug Deliv Rev 1996: 18: 273-82 
36. Rawlings AV, Scott IR, Harding CR, et al. Stratum corneum moisturisation at molecular level. J Invest Dermatol 1994; 103: 731-40

37. Elias PM, Feingold KR. Lipids and the epidermal water barrier: metabolism, regulation and pathophysiology. Semin Dermatol 1992; 11: 176-82

38. Menon GK, Feingold KR, Elias PM. The lamellar body secretory response to barrier disruption. J Invest Dermatol 1992; 98: 279-89

39. Fartasch M, Bassukas ID, Diepgen TH. Structural relationship between epidermal lipid lamellae, lamellar bodies and desmosomes in human epidermis: an ultrastructural study. Br J Dermatol 1993; 128: 1-9

40. Elias PM. The role of biological lipids in skin conditioning. In: Schueller $R$, Romanowski P, editors. Conditioning agents for hair and skin. New York: Marcel Dekker, 1999: 35-55

41. Mao-Quiang M, Jain M, Feingold KR, et al. Secretory phospholipase A2 activity is required for permeability barrier homeostasis. J Invest Dermatol 1996; 106: $57-63$

42. Holleran WM, Ginns EI, Menon GK, et al. Consequences of beta-glucocerebrosidase deficiency in epidermis: ultrastructure and permeability barrier alterations in Gaucher disease. J Clin Invest 1994; 93: 1756-64

43. Uchida $Y$, Hara $M$, Nishio $H$, et al. Epidermal sphingomyelins are precursors for selected stratum corneum ceramides. J Lipid Res 2000; 41: 2071-82

44. Schmuth M, Mao-Quiang M, Weber F, et al. Permeability barrier disorder in Nieman-pick disease: sphingomyelin-ceramide processing required for normal barrier homeostasis. J Invest Dermatol 2000; 115: 459-66

45. Brooks G, Idson B. Skin lipids. Int J Cosmet Sci 1991; 13: 103-13

46. Schaefer $\mathbf{H}$, Redelmeier TE. Skin barrier: principles of percutaneous absorption. Basel: Karger, 1996

47. Chang F, Swartzedrauber DC, Wertz PW, et al. Covalently bound lipids in keratinizing epithelia. Biochim Biophys Acta 1993; 1150: 98-102

48. Stewart ME, Downing DT. The $\omega$-hydroxyceramides of pig epidermis are attached to corneocytes solely through $\omega$-hydroxyl groups. J Lipid Res 2001; 42: 1105-10

49. Meguro S, Arai Y, Masukawa Y, et al. Relationship between covalently bound ceramides and transepidermal water loss (TEWL). Arch Dermatol Res 2000; 292: 463-8

50. Elias PM, Fartasch M, Crumrine D, et al. Origin of the corneocyte lipid envelope (CLE): observations in harlequin Ichthyosis and cultured human keratinocytes. J Invest Dermatol 2000; 115: 765-9

51. Cullis PR, Hope MJ. Physical properties and functional roles of lipids in membranes. In: Vance DE, Vance JE, editors. Biochemistry of lipids and membranes. Menlo Park: Benjamin Cummings, 1985: 25-72

52. Davis $\mathrm{J}$. The description of membrane lipid conformation, order and dynamics by 2H NMR. Biochim Biophys Acta 1983; 737: 117-71

53. Wertz PW, Downing DT. Epidermal lipids. In: Goldsmith LA, editor. Physiology, biochemistry and molecular biology of the skin. 2nd ed. Oxford: Oxford University Press, 1991: 205-235

54. Hedberg CL, Wertz PW, Downing DT. The time course of lipid biosynthesis in pig epidermis. J Invest Dermatol 1988; 91 : 169-74

55. Feingold KR. The regulation and role of epidermal lipid synthesis. Adv Lipid Res 1991; 24: $57-82$

56. Brod J. Characterization and physiological role of epidermal lipids. J Invest Dermatol 1991; 30: 84-90

57. Wertz PW, Miethke MC, Long SA, et al. The composition of the ceramides from human stratum corneum and from comedones. J Invest Dermatol 1985; 84: 410-2

58. Robson KJ, Stewart ME, Michelsen S, et al. 6-hydroxy-4-sphingenine in human epidermal ceramides. J Lipid Res 1994; 35: 2060-8

59. Wertz PW, Downing DT. Ceramides of pig epidermis: structure determination. J Lipid Res 1983; 24: 759-65

60. Stewart ME, Downing DT. A new 6-hydroxy-4-sphingenine-containing ceramide in human skin. J Lipid Res 1999; 40: 1434-9

61. Motta S, Monti M, Sesana S, et al. Ceramide composition of the psoriatic scale. Biochim Biophys Acta 1993; 1182: 147-51
62. Holleran WM, Mao-Quiang M, Gao WN, et al. Sphingolipids are required for mamalian epidermal barrier function: inhibition of sphingolipid synthesis delays barrier recovery after acute perturbation. J Clin Invest 1991; 88: 1338-45

63. Imokawa G, Akasaki S, Minematsu Y, et al. Importance of intercellular lipids in water-retention properties of the stratum corneum: induction and recovery study of surfactant dry skin. Arch Dermatol Res 1989; 281: 45-51

64. Wertz PW. The nature of epidermal barrier: biochemical aspects. Adv Drug Deliv Rev 1996; 18: 283-94

65. Schürer NY, Elias PM. The Biochemistry and function of stratum corneum lipids Adv Lipid Res 1991; 24: 27-56

66. Kerscher M, Korting HC, Scharfer-Korting M. Skin ceramides: structure and function. Eur J Dermatol 1991; 1: 39-43

67. Farin F, Lambers $\mathrm{H}$, Keuning W, et al. Human skin identical ceramides. Cosmet Toiletries 1995; $3:$ 126-32

68. Bouwstra JA, Gooris GS, Van der Speck JA, et al. The lipid and protein structure of mouse stratum corneum: a wide and small angle diffraction study. Biochem Biophys Acta 1994; 1212: 183-92

69. Forslind B. A domain mosaic model of the skin barrier. Acta Dermatol Venereol 1994; $74: 1-6$

70. Forslind B. A new look at the skin barrier: a biophysical and mechanical model for barrier function. J Appl Cosmetol 1994; 12: 63-72

71. Forslind B, Engström $S$, Engblom J, et al. A novel approach to the understanding of human skin barrier function. J Dermatol Sci 1997; 14: 115-25

72. White SH, Mirejovsky D, King GI. Structure of lamellar lipid domains and corneocyte envelopes of murine stratum corneum: an X-ray diffraction study. Biochemistry 1988; 27: 3725-32

73. McIntosh TJ, Stewart ME, Downing ET. X-ray diffraction of isolated skin lipids reconstitution of intercellular lipid domains. Biochemistry 1996; 35: 3649-53

74. Bouwstra JA, Thewalt J, Gooris GS, et al. A model membrane approach to the epidermal permeability barrier: an X-ray diffraction study. Biochemistry 1997; 36: $7717-25$

75. Shah J, Atienza JM, Rawlings AV, et al. Physical properties of ceramides: effect of fatty acid hydroxylation. J Lipid Res 1995; 36: 1945-55

76. Bouwstra JA, Pilgram G, Gooris G, et al. New aspects of the skin barrier organization. Skin Pharmacol Appl Skin Physiol 2001; 14 Suppl. 1: 52-62

77. Bouwstra JA. The skin barrier, a well-organized membrane. Colloids Surf A Physicochem Eng Asp 1997; 123-124: 403-13

78. López $\mathrm{O}$, Cócera $\mathrm{M}$, Campos $\mathrm{L}$, et al. Use of wide and small angle $\mathrm{X}$-ray diffraction to study the modifications in the stratum corneum induced by octyl glucoside. Colloids Surf A: Physicochem Eng Asp 2000; 162: 123-30

79. Pilgram GS, Engelsma-van Pelt AM, Oostergetel GT, et al. Study on the lipid organisation of stratum corneum lipid models by (cryo) electron diffraction. Lipid Res 1998; 39: 1669-76

80. Pilgram GS, Engelsma-van Pelt AM, Bouwstra JA, et al. Electron diffraction provides new information on human stratum corneum lipid organisation studied in relation to depth and temperature. J Invest Dermatol 1999; 133: 403-9

81. Swartzenruber DC, Wertz PW, Kitko DJ, et al. Molecular models of intercellular lipid lamellae in mamalian stratum corneum. J Invest Dermatol 1989; 92: 251-7

82. Caputo $R, G a s p a r i n i ~ G$. The freeze fracture replication technique in studies of skin In: Skerrow CJ, editor. Methods in skin research. Chichester: Wiley, 1985: 37-70

83. López $\mathrm{O}$, Cócera $\mathrm{M}, \mathrm{W}$ alter $\mathrm{P}$, et al. Octyl glucoside as a tool to induce structural modifications in the stratum corneum. Colloids Surf A 2000; 168: 115-23

84. Abraham W, Downing DT. Lamellar structures formed by stratum corneum lipids in vitro: a deuterium nuclear magnetic resonance (NMR) study. Pharmacol Res 1992; 9: 1415-21

85. Kitson N, Thewalt J, Lafleur M, et al. A model membrane approach to the epidermal permeability barrier. Biochemistry 1994; 33: 6707-15

86. White $\mathrm{R}$, Walker $\mathrm{M}$. Thermotropic and lyotropic behaviour of epidermal lipid fractions. Biochem Soc Trans 1980; 18: 881-2

87. Grotenhuis ET, Demel RA, Ponec M, et al. Phase behavior of stratum corneum lipids in mixed Langmuir-Blodgett monolayers. Biophys J 1996; 71: 1389-99 
88. Sparr E, Eriksson L, Bouwstra JA. AFM study of lipid monolayers: III phase behaviour of ceramides, cholesterol and fatty acids. Langmuir 2001; 17: 164-72

89. Moore DJ, Rerek ME, Mendelsohn R. Lipid domains and orthorombic phases in model stratum corneum: evidence from Fourier transform infrared spectroscopy studies. Biochem Biophys Res Commun 1997; 231: 797-801

90. Moore DJ, Rerek ME, Mendelsohn R. FTIR spectroscopy studies of the conformational order and phase behaviour ceramides. J Phys Chem 1997; 101: 8933-40

91. Moore DJ, Rerek ME, Mendelsohn R. Role of ceramides 2 and 5 in the structure of the stratum corneum lipid barrier. Int J Cosmet Sci 1999; 21: 353-68

92. Chen HC, Mendelson R, Rerek ME, et al. Fourier transform infrared spectroscopy and differential scanning calorimetry studies of fatty acid homogeneous ceramide 2. Biochim Biophys Acta 2000; 1468: 293-303

93. Chen HC, Mendelson R, Rerek ME, et al. Effect of cholesterol on miscibility and phase behavior in binary mixtures with synthetic ceramide 2 and octadecanoic acid: infrared studies. Biochim Biophys Acta 2001; 1512: 345-56

94. Bouwstra JA, Gooris GS, Salomonsde Vries MA, et al. Structure of human stratum corneum as a function of temperature and hydration: a wide-angle $\mathrm{X}$-ray diffraction study. Int J Pharm 1992; 84: 205-16

95. Bouwstra JA, Gooris GS, van der Spek JA, et al. The structure of human stratum corneum as determined by small angle X-ray scattering. J Invest Dermatol 1991 ; 96: 1006-14

96. Bouwstra JA, Gooris GS, Dubbelaar FER, et al. Role of ceramide 1 in the molecular organization of the stratum corneum lipids. J Lipid Res 1998; 39: 186-96

97. Imokava G, Abe A, Jin K, et al. Decreased level of ceramides in stratum corneum of atopic dermatitis: an etiologic factor in atopic dry skin. J Invest Dermatol 1991; 96: 523-6

98. Lavrijsen APM, Bouwstra JA, Gooris GS, et al. Reduced skin barrier function parallels abnormal stratum corneum lipid organisation in patients with lamellar ichthyosis. J Invest Dermatol 1995; 105: 619-24

99. Gay CL, Guy RH, Golden GM, et al. Characterization of low-temperature (i.e. $<65^{\circ} \mathrm{C}$ ) lipid transitions in human stratum corneum. J Invest Dermatol 1994; 103: 233-9

100. Golden GM, Guzek DB, Harris RR, et al. Lipid thermotropic transitions in human stratum corneum. J Invest Derm 1986; 86: 255-9

101. Golden GM, McKie JE, Potts RO. Role of stratum corneum lipid fluidity in transdermal drug flux. J Pharm Sci 1987; 76: 25-8

102. Naik A, Guy RH. Infrared spectroscopy and differential scanning calorimetry investigations of the human stratum corneum barrier function. In: Potts RO, Guy RH, editors. Mechanisms of transdermal drug delivery. New York: Marcel Dekker, 1997: 87-162

103. Moore DJ, Rerek ME. Recent biophysical studies of ceramides and their role in skin barrier function. Proc Cosmet Sci Conf 2000; 1: 36-43

104. López O, Cócera M, Parra JL, et al. Influence of ceramides in the solubilization of stratum corneum lipid liposomes by $\mathrm{Cl2}$-betaine/sodium dodecyl sulfate mixtures. Int J Pharm 1999; 187: 231-141

105. Petersen RD. Ceramides: key components for skin protection. Cosmet Toiletries 1992; 107: 45-9

106. Thestrup-Pedersen $\mathrm{K}$. How common are skin barrier problems? Yamanouchi Satellite Symposium 4th EADV Congress. Clinical Management of Skin Barrier Problems; 1995 Oct 10-15; Brussels, 5-8

107. De Paepe K. Evaluation of the efficacy of dermato-cosmetic products [PhD thesis]. Brussels: Vrije Universiteit Brussel, 2001

108. Lampe MA, Burlingame AL, Whitney J, et al. Human stratum corneum lipids: characterization and regional variations. J Lipid Res 1983; 24: 120-50

109. Ghadially RG, Brown BE, Sequeira-Martín SM, et al. The aged epidermal permeability barrier: structural, functional and lipid biochemical abnormalities in humans and a senescent murine model. J Clin Invest 1995; 95: 2281-90

110. Denda M, Koyama J, Hori J, et al. Age- and sex-dependent change in stratum corneum sphingolipids. Arch Dermatol Res 1993; 285: 415-7

111. Wefers H, Melnik BC, Flür M, et al. Influence of UV irradiation on the composition of human SC lipids. J Invest Dermatol 1991; 96: 959-62
112. Conti A, Rogers J, Verdejo P, et al. Seasonal influences on stratum corneum ceramide 1 fatty acids and the influence of topical essential fatty acids. Int J Cosmet Sci 1996; 18: 1-12

113. Motta S, Monti M, Sesana S, et al. Abnormality of water barrier function in psoriasis: role of ceramide fractions. Arch Dermatol 1994; 130: 452-6

114. Wertz PW, Cox PS, Squier CA, et al. Lipids of epidermis and keratinized and non-keratinized oral epithelia. Comp Biochem Physiol B 1986; 83: 529-31

115. Wertz PW, Kremer M, Squier SM. Comparison of lipids from epidermal and palatal stratum corneum. J Invest Dermatol 1992; 98: 375-8

116. Saint-Léger D, François AM, Lévêque JL, et al. Age-associated changes in stratum corneum lipids and their relation to dryness. Dermatologica 1988; 177: 159-64

117. Rawlings AV, Rogers J, Mayo AM. Changes in lipids in the skin aging process. Biocosmet Skin Aging 1993; 1: $31-45$

118. Rogers J, Harding C, Mayo A, et al. Stratum corneum lipids: the effect of ageing and the seasons. Arch Dermatol Res 1996; 288: 765-70

119. Jin K, Higaki Y, Takagi Y, et al. Analysis of beta-glucocerebrosidase and ceramidase activities in atopic and aged dry skin. Acta Derm Venereol 1994; 74: 337-40

120. Yamamura $T$, Tezuka $T$. Change in sphingomyelinase activity in human epidermis during ageing. J Dermatol Sci 1990; 1: 79-84

121. Fartasch M, Bassukas ID, Diepgen T. Disturbed extruding mechanism of lamellar bodies in dry non-eczematous skin of atopics. Br J Dermatol 1992; 127: 221-7

122. Yoshikawa N, Imokawa G, Akimoto $K$, et al. Regional analysis of ceramides within the stratum corneum in relation to seasonal changes. Dermatology 1994; 188: $207-14$

123. Rawlings A, Hope J, Rogers J, et al. Abnormalities in stratum corneum structure, lipid composition and desmosome degradation in soap induced winter xerosis. J Soc Cosmet Chem 1994; 45: 203-20

124. Burr G, Burr M. A new deficiency disease produced by rigid exclusion of fat from diet. J Biol Chem 1929; 82: 345-67

125. Hou S, White S, Menon G, et al. Membrane structures in normal and essential fatty acid deficient stratum corneum: characteristics by ruthenium tetroxide staining and X-ray diffraction. J Invest Dermatol 1991; 96: 216-23

126. Yumamoto A, Serizawa $M$, Ito $M$, et al. Stratum corneum lipid abnormalities in atopic dermatitis. Arch Dermatol Res 1991; 283: 219-23

127. Brod J, Traitler H, Studer A, et al. Evolution of lipid composition in kin treated with blackcurrant seed oil. Int J Cosmet Sci 1988; 10: 149-59

128. Schreiner V, Gooris GS, Pfeiffer S, et al. Barrier characteristics of different human skin types investigated with X-Ray diffraction, lipid analysis and Electron Microscopy Imaging. J Invest Dermatol 2000; 114: 654-60

129. Kompaore F, Dupont C, Marty JP. In vivo evaluation in man by two-invasive methods of the stratum corneum barrier function after physical and chemical modification. Int J Cosmet Sci 1991; 13: 293-302

130. Elias PM, Ansel JC, Wood LC, et al. Signalling networks in barrier homeostasis: the mystery widens. Arch Dermatol 1996; 132: 1505-6

131. Grubauer G, Feingold KR, Elias PM. Relationship of epidermal lipogenesis to cutaneous barrier function. J Lipid Res 1987; 28: 746-52

132. Holleran WM, Gao WN, Feingold KR, et al. Localisation of epidermal sphingolipid synthesis and serine palmitoyl transferase activity: alterations imposed by permeability requirements. Arch Dermatol Res $1995 ; 287: 254-8$

133. Feingold KR. Permeability barrier homeostasis, its biochemical basis and regulation. Cosmet Toiletries 1997; 112:49-59

134. López $\mathrm{O}$, Walter $\mathrm{P}, \mathrm{Cócera} \mathrm{M}$, et al. Structural modifications in the stratum comeum by effect of different solubilizing agents: a study based on high-resolution lowtemperature scanning electron microscopy. Skin Pharmacol Appl Skin Physiol $2000 ; 13: 265-72$

135. Fulmer AW, Kramer GJ. Stratum corneum lipid abnormalities in surfactant-induced dry scaly skin. J Invest Dermatol 1986; 86: 598-602

136. Treffel P, Gabard B. Measurement of sodium lauryl sulfate skin irritation. Acta Derm Venereol 1996; 76: 341-3

137. Di Nardo A, Sugino $K$, Wertz $P$, et al. Sodium lauryl sulfate (SLS) induced irritant contact dermatitis: a correlation study between ceramides and in vivo parameters of irritation. Contact Dermatitis 1996; 35: 86-91 
138. Di Nardo A, Sugino K, Ademola J, et al. Role of ceramides in proclivity to toluene and xylene-induced skin irritation in man. Derm Beruf Umwelt 1996; 44: 119-25

139. Berardesca E, Anderson PH, Bjerring $P$, et al. Erythema induced by organic solvents: in vivo evaluation of oxygenized and deoxygenated hemoglobin by reflectance spectroscopy. Contact Dermatitis 1992; 27: 8-11

140. Jacobs G, Castellazi A, Dierickx PJ. Evaluation of a non-invasive human and in vitro cytotoxicity method as alternatives to the skin irritation test on rabbit. Contact Derm 1989; 21: 239-44

141. Wahlberg JE. Erythema-inducing effects of solvents following topical administrations. Derm Beruf Umwelt 1984; 32: 91-4

142. Grubauer G, Feingold KR, Harris RM, et al. Lipid content and lipid type as determinant of the epidermis permeability barrier. J Lipid Res 1989; 30: 89-96

143. Proksch E, Feingold KR, Mao-Qiang M, et al. Barrier function regulates epidermal DNA synthesis. J Invest Dermatol 1991; 87: 1668-73

144. Motta S, Sesana S, Monti M, et al. Interlamellar lipid differences between normal and psoriatic stratum corneum. Acta Derm Venereol Suppl (Stockh) 1994; 186: 131-2

145. Ilzuka $\mathrm{H}$, Ishida-Yamamoto $\mathrm{A}$, Honda $\mathrm{H}$. Epidermal remodelling in psoriasis. $\mathrm{Br}$ J Dermatol 1996; 135: 433-8

146. Fartasch M. Epidermal barrier in disorders of the skin. Microse Res Tech 1997; 38: $361-72$

147. Alessandrini F, Stachowitz S, Ring J, et al. The level of prosaposin is decreased in the skin of patients with psoriasis vulgaris. J Invest Dermatol 2001; 116: $394-400$

148. Werner $Y$, Lindberg M, Forslind B. Membrane-coating granules in "dry" noneczematous skin of patients with atopic dermatitis. Acta Derm Venereol 1987; 67: $385-90$

149. Melnik B, Hollman J, Plewig G. Decreased stratum corneum ceramides in atopic individuals: a patobiochemical factor in xerosis. Br J Dermatol 1988; 119 : 547-9

150. Melnik B, Hollman J, Hofmann U. Lipid composition of outer stratum corneum and nails in atopic and control subjects. Arch Dermatol Res 1990; 282: 549-51

151. Imokawa $G$, Abe A, Jin $K$, et al. Decreased level of ceramides in stratum corneum of atopic dermatitis: and etiologic factor in atopic dry skin? J Invest Dermatol 1991; 96: 523-6

152. Yamamoto A, Serizawa $S$, Ito $M$, et al. Stratum corneum lipid abnormalities in atopic dermatitis. Arch Dermatol Res 1991; 238: 219-23

153. Murata $Y$, Ogata J, Higaki Y, et al. Abnormal expression of sphingomyelin acylase in atopic dermatitis: an etiologic factor for ceramide deficiency? J Invest Dermatol 1996; 106: 1242-9

154. Di Nardo A, Wertz P, Giannetti A, et al. Ceramide and cholesterol composition of the skin of patients with atopic dermatitis. Acta Derm Venereol (Stockh) 1998; 78: 27-30

155. Williams ML. Lipids in normal and pathological desquamation. In: Elias PM, editor. Advances in lipid research. Vol 24. San Diego (CA): Academic Press, 1991: 211-62

156. Paige DG, Morse-Fischer N, Harper JI. Quantification of stratum corneum ceramides and lipid envelope ceramides in the hereditary ichthyoses. $\mathrm{Br} \mathrm{J}$ Dermatol 1994; 131: 23-7

157. Hamanaka S, Ujihara M, Serizawa S, et al. A case of recessive X-linked ichthyosis: scale-specific abnormalities of lipid composition may explain the pathogenesis of the skin manifestation. J Dermatol 1997; 24: 156-60

158. Berra B, Adorni L, Ciuffo R, et al. Skin lipid abnormalities in Gaucher's disease. J Appl Cosmetol 2000; 18: 113-23

159. Jensen JM, Schütze $S$, Neumann $C$, et al. Impaired cutaneous permeability barrier function, skin hydration and sphingomyelinase activity on Keratin 10 deficient mice. J Invest Dermatol 2000; 115: 708-13

160. Saint-Léger D, François AM, LÊvêque JL, et al. Stratum corneum lipids in skin xerosis. Dermatologica 1989; 178: $151-5$

161. Akimoto $\mathrm{K}$, Yoshikawa N, Higaki Y, et al. Quantitative analyses of stratum corneum lipids in xerosis and asteatotic eczema. J Dermatol 1993; 20: 1-6
162. Berardesca E, Fideli D, Borroni G, et al. In vivo hydration and water retention capacity of stratum corneum in clinically uninvolved skin in atopic and psoriatic patients. Acta Derm Venereol (Stockh) 1990; 70: 400-4

163. Sedenari S, Giusti G. Objective assessment of the skin of children affected by atopic dermatitis: a study on $\mathrm{pH}$, capacitance and TEWL in eczematous and clinically uninvolved skin. Acta Derm Venereol (Stockh) 1995; 75: 429-33

164. Matsumoto $M$, Umemoto $\mathrm{N}$, Sugiura $\mathrm{H}$, et al. Difference in ceramide composition between "dry" and "normal" skin patients with atopic dermatitis. Acta Derm Venereol (Stockh) 1999; 79: 246-7

165. Ghadially R, Williams ML, Hou SYE, et al. Membrane structural abnormalities in the stratum corneum of the autosomal recessive ichthyosis. J Invest Dermatol 1992; 99: 755-63

166. Tupker RA, Pinagoda J, Coenraads PJ, et al. Susceptibility to irritants: role of barrier function, skin dryness and history of atopic dermatitis. Br J Dermatol 1990; 123: 199-205

167. Downing DT, Stewart ME, Wertz PW, et al. Essential fatty acids and acne. J Am Acad Dermatol 1986; 14: $221-5$

168. Perisho K, Wertz PW, Madison KC, et al. Fatty acids of acylceramides from comedones and from the skin surface of acne patients and control subjects. $\mathrm{J}$ Invest Dermatol 1988; 90: 350-3

169. Berardesca E, Vignoli GP, Oresajo C, et al. Prevention of barrier function damage by topically applied ceramides. Proceedings of the 17th IFSCC International Congress; 1992 Oct 13-16; Yokohama, 881-8

170. Mao-Quiang M, Feingold KR, Elias PM. Exogenous lipids influence permeability barrier recovery in acetone-treated murine skin. Arch Dermatol 1993; 129: 728-38

171. Yang L, Mao-Quiang M, Taljebini M, et al. Topical stratum corneum lipids accelerate barrier repair after tape stripping, solvent treatment and some but not all types of detergent treatment. $\mathrm{Br}$ J Dermatol 1995; 133: 679-85

172. Mao-Quiang M, Feingold KR, Thomfeldt $C R$, et al. Optimization of physiological lipid mixtures for barrier repair. J Invest Dermatol 1996; 106: 1096-101

173. Mao-Quiang $M$, Feingold $K R$, Wang F, et al. A natural lipid mixture improves barrier function and hydration in human and murine skin. J Soc Cosmet Chem 1997; 47: 157-66

174. Linter K, Mondon P, Girard F, et al. The effect of synthetic ceramide-2 on transepidermal water loss after stripping or SLS treatment: an in vivo study. Int J Cosmet Sci 1997; 19: 15-25

175. López $\mathrm{O}$, Cócera $\mathrm{M}$, Walter $\mathrm{P}$, et al. Effect of liposomes on delipidized stratum corneum structure: an "in vitro" study based on high resolution low temperature scanning electron microscopy. Colloids Surf A: Physiochem Eng Asp 2001; 182: 35-42

176. De Paepe K, Derde MP, Roseeuww D, et al. Incorporation of Ceramide 3B in dermatocosmetic emulsions: effect on the TEWL of SLS-damaged skin. J Eur Acad Dermatol Venereol 2000; 14: 272-9

177. Imokawa $G$, Akasaki $S$, Hattori $M$, et al. Selective recovery of deranged waterholding properties by stratum corneum lipids. J Invest Dermatol 1986; 87: 758-61

178. Imokawa G, Akasaki S, Kawamata A, et al. Water-retaining function in the stratum corneum and its recovery properties by synthetic pseudoceramides. J Soc Cosmet Chem 1989; 40: 273-85

179. De Paepe K, Vandamme P, Derde MP, et al. Body lotions enriched with skin identical lipids: a TEWL study of aged skin and SLS-induced scaly skin. Euro Cosmetics 1999; 7: 38-45

180. De Paepe K, Roseeuw D, Rogiers V. Repair of acetone and SLS damaged human skin barrier function by topically applied emulsions containing barrier lipids. J Eur Acad Dermatol Venereol 2002; 16: 587-94

181. Rodrigues L, Amores da Silva P, Pinto $P$, et al. Identification of the in vivo topically applied "human-identical" ceramides included in negatively charged liposomes. Boll Chim Farma 1998; 137: 395-402

182. De Paepe K, Roseeuw D, Rogiers V. Effect of ceramides-containing lotions on the barrier function of the skin. In: Conference proceedings, active ingredients. Tunbridge Wells: Step Publishing, 1998: 121-32 
183. de Pera M, Coderch L, Fonollosa J, et al. Effect of internal wool lipid liposomes on skin repair. Skin Pharmacol Appl Skin Physiol 2000; 13: 188-95

184. Coderch L, de Pera M, Fonollosa J, et al. Efficacy of stratum corneum lipid supplementation on human skin. Contact Dermatitis $2002 ; 47: 139-46$

185. Hatziantoniou S, Rallis M, Demetzos C, et al. Pharmacological activity of natural lipids on a skin barrier disruption model. Pharmacol Res 2000; 42: 55-9

186. Schmid MH, Korting HC. Liposomes for atopic dry skin: the rationale for a promising approach. Clin Investig 1993; 71: 649-53

187. Korting HC, Zienicke $H$, Schäfer-Korting M, et al. Liposome encapsulation improve efficiency of betamethasone dipropionate in atopic eczema but not in psoriasis vulgaris. Eur J Clin Pharmacol 1990; 39: 349-51

188. Chamlin SL, Frieden IJ, Fowler A, et al. Ceramide-dominant, barrier-repair lipids improve childhood atopic dermatitis. Arch Dermatol 2001; 137: 1110-2

189. Prottey C, Hartop PJ, Press M. Correction of the cutaneous manifestations of essential fatty acid deficiency in man by application of sunflower seed oil to the skin. J Invest Dermatol 1975; 64: 228-34

190. Fartasch M, Teal J, Menon GK. Mode of action of glycolic acid on human stratum corneum: ultrastructural and functional evaluation of the epidermal barrier. Arch Dermatol Res 1997; 289: 404-9

191. Rawlings AV, Davies A, Carlomusto M, et al. Effect of lactic acid isomers on keratinocyte ceramide synthesis, stratum corneum lipid levels and stratum corneum barrier function. Arch Dermatol Res 1996: 288: 383-90

192. Zhang K, Kosturko R, Rawlings AV. The effect of thiols on epidermal lipid biosynthesis [abstract]. J Invest Dermatol 1995; 104: 687

193. Carlomusto M, Pillai K, Rawlings AW. Human keratinocytes in vitro can utilise exogenously supplied sphingolipid analogues for keratinocyte ceramide biosynthesis [abstract]. J Invest Dermatol 1996; 106: 919

194. Davies A, Verdejo P, Feinberg C, et al. Increased stratum corneum ceramide levels and improved barrier function following treatment with tetracetylphytosphingosine. J Invest Dermatol 1996; 106: 918-1000

195. Spiegel S, Merrill AH. Sphingolipid metabolism and cell growth regulation. FASEB J 1996; 10: 1388-97

196. Hunnan YA. Functions of ceramides in coordinating cellular responses to stress. Science 1996: 274: 1855-9
197. Merrill AH, Schmelz EM, Dillehay DL, et al. Sphingolipids. Enigmatic lipid class: biochemistry, physiology and pathophysiology. Toxicol Appl Pharmacol 1997; 142: 208-25

198. Pillai K, Frew L, Cho S, et al. Synergy between the vitamin D precursor, 25 hydroxyvitamin $\mathrm{D}$ and short chain ceramides on human keratinocyte growth and differentiation. J Invest Dermatol Suppl 1996; 1: 39-45

199. Carlomusto M, Mahajan M, Pillai S. Vitamin D-mediated keratinocyte differentiation does not involve sphingomyelin hydrolysis [abstract]. J Invest Dermatol 1997; 108: 660

200. Tanno O, Ota Y, Kitamura N, et al. Nicotinamide increases biosynthesis of ceramides as well as other stratum corneum lipids to improve the epidermal permeability barrier. Br J Dermatol 2000; 143: 524-31

201. Ponec M, Weerheim A, Kempenaar J, et al. The formation of competent barrier lipids in reconstructed human epidermis requires the presence of vitamin C. J Invest Dermatol 1997; 109: 348-55

202. Marsh NN, Elias PM, Holleran WM. Glucosylceramides stimulate murine epidermal hyperproliferation. J Clin Invest 1995; 95: 2903-9

203. Uchida $Y$, Iwamori $M$, Nagai $Y$. Activation of keratinisation of keratinocytes from fetal rat skin with $\mathrm{N}$ (lineoyl) $\omega$-hydroxy fatty acyl sphingosyl glucose as a marker of epidermis. Biochim Biophys Res Commun 1990; 179: 162-8

204. Bosko C, Samares S, Santanastasio $\mathrm{H}$, et al. Influence of fatty acid composition of acylceramides on keratinocyte differentiation [abstract]. J Invest Dermatol 1996; 106: 871

205. Harding $C R$, Watkinson $A$, Rawlings $A V$, et al. Dry skin, moisturization and corneodesmolysis. Int J Cosmet Sci 2000; 22: 21-52

Correspondence and offprints: Dr Luisa Coderch, Instituto de Investigaciones Químicas y Ambientales de Barcelona, Jordi Girona 18-26, Barcelona 08034, Spain.

E-mail: Icnesl@cid.csic.es 